\title{
TANQUE METÁLICO PARA RESERVAÇÃO DE ÁGUA NO BRASIL: UM ESTUDO DA APLICAÇÃO PARCIAL DA NORMA API 650
}

\section{ARTIGO ORIGINAL}

RASI, José Roberto ${ }^{1}$

CAUNETTO, Donizete ${ }^{2}$

BROETTO, Jonathan Figueiredo ${ }^{3}$

RASI, José Roberto. CAUNETTO, Donizete. BROETTO, Jonathan Figueiredo. Tanque metálico para reservação de água no Brasil: um estudo da aplicação parcial da norma API 650. Revista Científica Multidisciplinar Núcleo do Conhecimento. Ano 05, Ed. 05, Vol. 01, pp. 33-62. Maio de 2020. ISSN: 2448-0959, Link de acesso: https://www.nucleodoconhecimento.com.br/engenharia-civil/tanque$\underline{\text { metalico }}$

\section{RESUMO}

Com a crescente demanda por reservação de água e pela falta de normas técnicas para reservatórios metálicos no Brasil, vários fabricantes de reservatórios têm utilizado parcialmente a norma API 650 para dimensionamento e verificação desses reservatórios. Neste trabalho, foram realizados estudos para a verificação da aplicação parcial e integral da norma API 650, método 1 pé, através de dimensionamento de 7 tanques metálicos com o mesmo volume em função de diferentes relações altura/diâmetro $(H / D)$. Analisa - se as tensões circunferenciais nos

1 Mestrado em Estruturas e Construção Civil; Especialização em Construções Industriais; Especialização em Engenharia Ambiental; Especialização em Engenharia de Segurança; Engenheiro Civil, e Engenheiro de Operação Mecânico.

2 Especialização em Engenharia de estruturas e Engenharia Civil.

${ }^{3}$ Engenheiro Civil. 
dois casos e dimensionamento previsto na API 650 e determina as relações altura/diâmetro mais econômicas para o armazenamento de água.

Palavras chave: Tanque metálico, norma API 650, dimensionamento, otimização.

\section{INTRODUÇÃO}

Tanques cilíndricos são estruturas normalmente utilizadas para o armazenamento de água, de resíduos industriais, de resíduos da indústria petroquímica, de óleos, de grãos e etc. (HECKE, 2010).

Segundo Barros (2010), são equipamentos de caldeiraria pesada, sujeitos à pressão aproximadamente atmosférica, normalmente na faixa de 0 a 0,5 psi e destinados principalmente, ao armazenamento de petróleo e seus derivados.

Roncetti (2011) afirma que houve aumento da demanda por estocagem de graneis líquidos nas mais variadas atividades econômicas e também o aumento de demanda para atividades intermediarias como o saneamento, tratamento de rejeitos, refrigeração e demais processos fabris, onde é necessário estocar graneis líquidos. A Figura 1ilustra os vários tipos de tanque de armazenamento que são comumente utilizados pelas industrias (KUAN, 2009).

Figura 1 - Tipos de tanque de armazenamento.

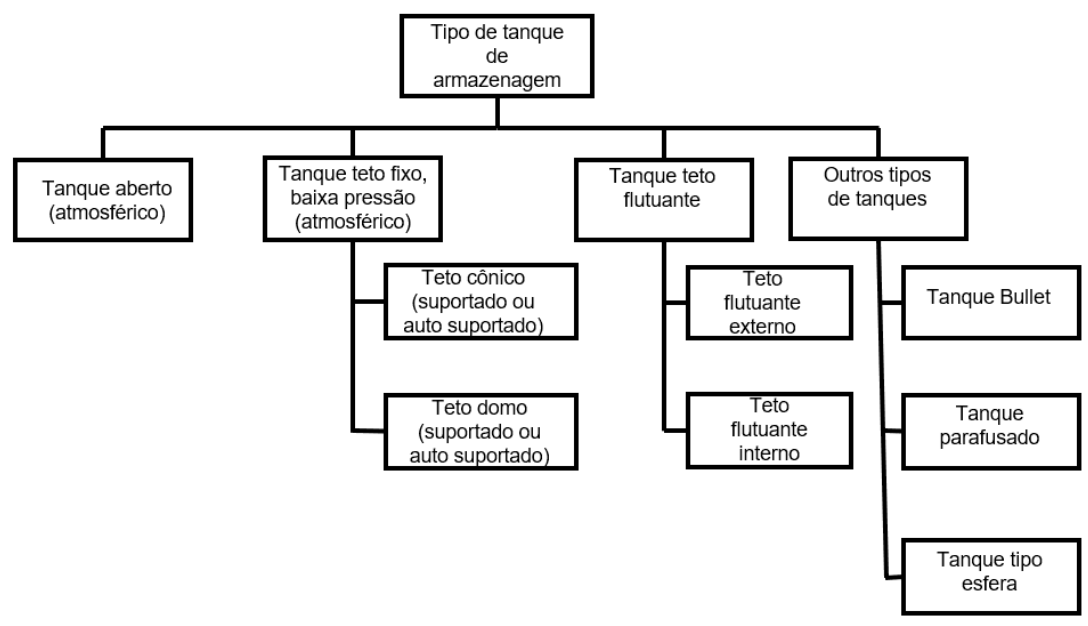

Fonte: Kuan, 2009. 
O projeto e a construção de tanques cilíndricos atmosféricos envolvem uma série de cuidados especiais e exige o conhecimento de normas técnicas e materiais adequados para cada tipo de aplicação, pois falhas nesses equipamentos podem acarretar grandes prejuízos financeiros ou, até mesmo, perdas de vidas (NUNES, 2013).

No Brasil, existe norma para a construção destes equipamentos. A norma NBR 7821 - Tanques Soldados para Armazenamento de Petróleo e Derivados - publicada pela Associação Brasileira de Normas Técnicas (ABNT). Porém, a norma mais utilizada nas indústrias em geral é a norma regulamentadora americana API 650 - Welded Steel Tanks for Oil Storage - do American Petroleum Institute (API), ambas destinadas à reservação de petróleo e derivados (SATO, 2015).

De acordo com Barros (2010), a API 650 Abrange especificações sobre material, projeto, fabricação, montagem e testes de tanques de armazenamento verticais, cilíndricos, não enterrados, com o topo fechado ou aberto, de construção soldada, com várias dimensões e capacidades, para serviço não refrigerado, com temperatura de projeto máxima de $260^{\circ} \mathrm{C}$ e pressão interna aproximadamente atmosférica (não superior a 2,5 psig).

Segundo Azzumi e Guzey (2015), em conformidade com a norma API 650, os três métodos para determinar a espessura do reservatório dos tanques de armazenamento cilíndricos de aço projetados em conformidade com a norma API 650, são:

O método de um pé (1FM - one foot method), o método de ponto de projeto variável (VDM) e a análise linear. Comparamos os projetos de casca com base nesses três métodos para diferentes propriedades do tanque: diâmetro, altura e tensão permitida.

O método de um pé (1FM), que é baseado na " teoria da membrana ". A espessura necessária da placa de casca para cada curso de casca é calculado usando a tensão circunferencial em um ponto de 0,3 m (1 pé) acima da costura horizontal de solda inferior da virola da carcaça, devido à pressão hidrostática do líquido armazenado. $\mathrm{O}$ $1 F M$ é usado com sucesso para a maioria dos tanques. No entanto, o projetos 
baseados no $1 \mathrm{FM}$ podem se tornar conservadores e proibitivos de custos para tanques de maior diâmetro. Portanto, a API 650 limita o aplicabilidade deste método a tanques de até $61 \mathrm{~m}$ (200 pés) em diâmetro.

O segundo método para calcular a espessura necessária da placa de casca é o método do ponto de design variável (VDM) que também é baseado na "teoria da membrana". O VDM foi proposto por Zick e McGrath em 1968 e posteriormente adotado pela API 650 como um refinado método para calcular a espessura necessária da placa de casca, especialmente para tanques com mais de $61 \mathrm{~m}$ (200 pés) de diâmetro. O VDM leva em consideração a restrição fornecida pelas placas do fundo do tanque para o primeiro percurso da virola e a restrição fornecida por cada virola inferior para o percurso da virola superiora. O VDM usa uma distância variável em vez de distância fixa de 0,3 m (1 pé), como usado em 1FM, acima da solda (costura) circunferencial para cada percurso da virola, para calcular a máximo tensão circunferencial devido à pressão hidrostática.

O terceiro método fornecido na API 650 é o cálculo da espessura da casca usando análise linear. Nesta abordagem, as condições de contorno para a análise deve ser um momento plástico relacionado ao rendimento de placa sob a concha e movimento radial totalmente restrito o fundo da concha. API 650 não descreve um específico método de análise linear. Neste estudo, desenvolvemos um novo método usando teoria da casca fina para realizar uma análise linear da espessura da casca Cálculo. Neste método, estamos usando rigidez exata - flexibilidade relações e funções exatas da forma originárias do chamado Solução "casca curta " das equações que governam a partir da fina teoria da casca elástica.

Constatou-se pouca informação literária para cálculo de reservatório metálico destinado a reservação de água e a falta de normas técnicas especificas para tanques soldados para armazenamento de água no Brasil.

Devido à falta de norma técnica especifica, tem se utilizado como parâmetro de cálculo para reservatórios metálicos destinados a reservação de água, a API 650 na sua integralidade ou apenas parcialmente, especificamente no que se refere a 
determinação de espessuras dos costados dos tanques e tensões admissíveis, uma vez que os critérios de segurança quanto à incêndios e explosões do material armazenado não se aplicariam para a água.

\section{MATERIAL E MÉTODO}

O objetivo principal deste trabalho é verificar o dimensionamento de tanques metálicos aberto, sem teto, com o mesmo volume e diferentes H/D, de acordo com a norma API 650 , pelo método de um pé (1FM), em duas etapas, sendo a primeira considerando apenas as espessuras calculadas pela equação descrita no item 5.6.3.2 da referida norma;

$$
t_{d}=\frac{4.9 D(H-0.3) G}{S_{d}}+C A
$$

Onde:

$t_{d}=$ espessura de projeto, em $\mathrm{mm}$;

$\mathrm{D}$ = diâmetro nominal do tanque, em m;

$\mathrm{H}$ = nível de projeto do liquido, em m;

$\mathrm{G}$ = peso específico do liquido, no caso de água: 1;

$\mathrm{CA}=$ sobrespessura de corrosão, especificada pelo comprador, em mm;

$S_{d}=$ tensão admissível (tabela 5-2 API 650), em Mpa.

E na segunda etapa, além da verificação da espessura calculada pela Equação 1, adotam-se também as espessuras mínimas, conforme descrito no item 5.6.1.1 e mostrados na tabela 1. 
Tabela 1 - Espessuras mínimas do costado

\begin{tabular}{ccccc}
\hline \multicolumn{2}{c}{ Nominal Tank Diameter } & & \multicolumn{2}{c}{ Nominal Plate Thickness } \\
\cline { 1 - 3 }$(\mathrm{m})$ & $(\mathrm{ft})$ & 5 & (in.) \\
\hline$<15$ & $<50$ & 6 & $3 / 16$ \\
15 to $<36$ & 50 to $<120$ & 8 & $1 / 4$ \\
36 to 60 & 120 to 200 & 10 & $5 / 16$ \\
$>60$ & $>200$ & & $3 / 8$
\end{tabular}

Fonte: API 650 (2007)

Como objetivo complementar, determinar a faixa de relação $H / D$ que é a mais economicamente viável, com menor peso de construção do tanque soldado.

O critério para se determinar a relação entre a altura $(H)$ e diâmetro $(D)$ dos modelos é o volume do reservatório, mantido constante, com $660,00 \mathrm{~m}^{3}$ e diâmetro máximo menor que 15,00 m de acordo com o item 5.6.1.1 - API 650, mostrado na tabela 1. Em decorrência, para o volume constante $\left(\mathrm{V}_{0}\right)$ e consideradas as relações altura / diâmetro (H/D) entre 0,25 e 4,0.

Definidos: $\mathrm{H}$ = altura do cilindro; $\mathrm{D}=$ diâmetro e $\mathrm{V}=$ volume $=$

$$
\pi \cdot \frac{D^{2}}{4} \cdot H
$$

As dimensões dos diâmetros, das alturas e as proporções entre elas estão descritas na tabela 2 e na figura 2.

Tabela 2 - Relações Altura / Diâmetro para volume constante de 660,00 m³

\begin{tabular}{c|r|r|r|r|r|r|r}
\hline $\mathbf{H} / \mathbf{D}$ & \multicolumn{1}{|c|}{$\mathbf{4 , 0 0}$} & \multicolumn{1}{|c|}{$\mathbf{3 , 0 0}$} & \multicolumn{1}{|c|}{$\mathbf{2 , 0 0}$} & \multicolumn{1}{|c|}{$\mathbf{1 , 5 0}$} & \multicolumn{1}{|c|}{$\mathbf{1 , 0 0}$} & \multicolumn{1}{c}{$\mathbf{0 , 5 0}$} & \multicolumn{1}{c}{$\mathbf{0 , 2 5}$} \\
\hline $\mathrm{D}[\mathrm{m}]$ & 14,98 & 13,61 & 11,89 & 10,80 & 9,43 & 7,49 & 5,94 \\
\hline $\mathrm{V}\left[\mathrm{m}^{3}\right]$ & 660,00 & 660,00 & 660,00 & 660,00 & 660,00 & 660,00 & 660,00 \\
\hline $\mathrm{H}[\mathrm{m}]$ & 3,75 & 4,54 & 5,94 & 7,20 & 9,43 & 14,98 & 23,77 \\
\hline
\end{tabular}

Fonte: O próprio autor 
Figura 2 - Modelos geométricos dos reservatórios cilíndricos estudados

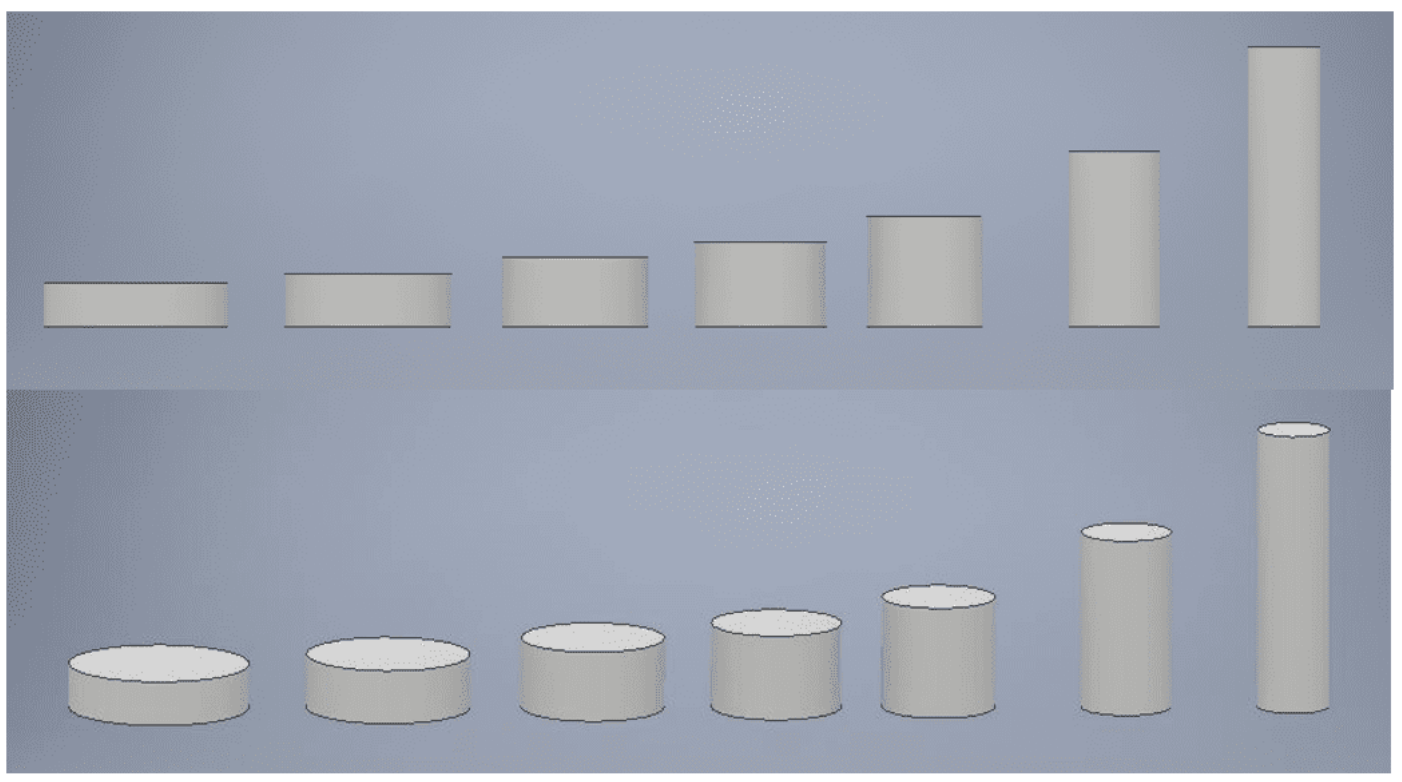

Fonte: O próprio autor

O aço empregado é o ASTM A36, caracterizado por um módulo de elasticidade (E) igual a 205.000 Mpa, coeficiente de Poisson ( $\mu$ ) igual a 0,30, densidade ( $\mathrm{\gamma}$ ) de 77.000 $\mathrm{N} / \mathrm{mm}^{3}$, tensão de escoamento $\mathrm{f}_{\mathrm{y}}=250,00 \mathrm{Mpa}$ e tensão última $\mathrm{f}_{\mathrm{u}}=400,00 \mathrm{Mpa}$. De acordo com a tabela 5-2 Permissible Plate Materials and Allowable Stresses da API 650, a tensão admissível para o aço ASTM A36 é de 160,00 Mpa (tabela 3).

Tabela 3 - Materiais planos permitidos e tensões admissíveis

Table 5-2_Permissible Plate Materials and Allowable Stresses

\begin{tabular}{|c|c|c|c|c|c|}
\hline $\begin{array}{c}\text { Plate } \\
\text { Specification }\end{array}$ & Grade & $\begin{array}{l}\text { Minimum } \\
\text { Yield Strength } \\
\mathrm{MPa}(\mathrm{psi})\end{array}$ & $\begin{array}{c}\text { Minimum } \\
\text { Tensile Strength } \\
\mathrm{MPa}(\mathrm{psi})\end{array}$ & $\begin{array}{c}\text { Product } \\
\text { Design Stress } S_{d} \\
\mathrm{MPa}(\mathrm{psi})\end{array}$ & $\begin{array}{l}\text { Hydrostatic } \\
\text { Test Stress } S_{t} \\
\mathrm{MPa}(\mathrm{psi})\end{array}$ \\
\hline \multicolumn{6}{|c|}{ ASTM Specifications } \\
\hline A $283 \mathrm{M}$ (A 283) & $\mathrm{C}(\mathrm{C})$ & $205(30,000)$ & $380(55,000)$ & $137(20,000)$ & $154(22,500)$ \\
\hline A $285 \mathrm{M}$ (A 285 ) & $\mathrm{C}(\mathrm{C})$ & $205(30,000)$ & $380(55,000)$ & $137(20,000)$ & $154(22,500)$ \\
\hline A $131 \mathrm{M}$ (A 131) & $\begin{array}{l}\text { A, B, CS } \\
(A, B, C S)\end{array}$ & $235(34,000)$ & $400(58,000)$ & $157(22,700)$ & $171(24,900)$ \\
\hline A 36M (A 36) & - & $250(36,000)$ & $400(58,000)$ & $160(23,200)$ & $171(24,900)$ \\
\hline A $131 \mathrm{M}$ (A 131) & EH 36 (EH 36) & $360(51,000)$ & $490^{\mathrm{a}}\left(71,000^{\mathrm{a}}\right)$ & $196(28,400)$ & $210(30,400)$ \\
\hline A $573 \mathrm{M}$ (A 573) & $400(58)$ & $220(32,000)$ & $400(58,000)$ & $147(21,300)$ & $165(24,000)$ \\
\hline A $573 \mathrm{M}$ (A 573) & $450(65)$ & $240(35,000)$ & $450(65,000)$ & $160(23,300)$ & $180(26,300)$ \\
\hline A $573 \mathrm{M}$ (A 573) & $485(70)$ & $290(42,000)$ & $485^{\mathrm{a}}\left(70,000^{\mathrm{a}}\right)$ & $193(28,000)$ & $208(30,000)$ \\
\hline A $516 \mathrm{M}$ (A 516) & $380(55)$ & $205(30,000)$ & $380(55,000)$ & $137(20,000)$ & $154(22,500)$ \\
\hline
\end{tabular}

Fonte: API 650 (2007) - modificado pelo autor. 
As espessuras das chapas do corpo de reservatório são consideradas variáveis ao longo da altura do reservatório (figura 3).

Figura 3 - Variação das chapas ao longo da altura do reservatório

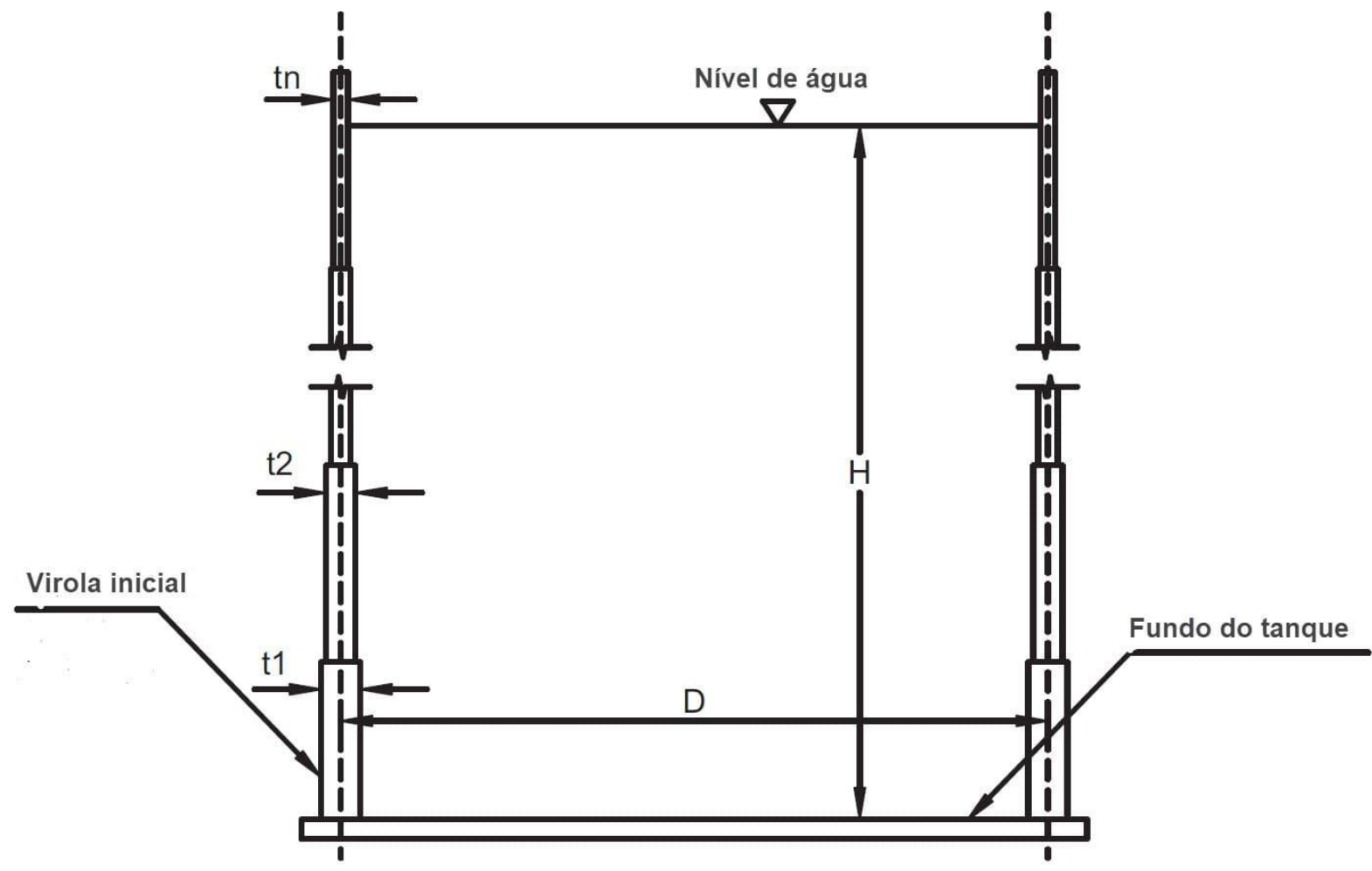

Fonte: Adaptado de Azzumi e Guzey (2015)

Considerando a não existência de atrito devido ao material armazenado (água), a condição do reservatório estar completamente cheio, a não aplicação de vento e as condições das espessuras das chapas dos corpos dos reservatórios (virolas), resulta apenas 1 (um) caso de análise (Figura 4): 
Figura 4 - Tanque com liquido e espessura de parede variável ao longo da altura

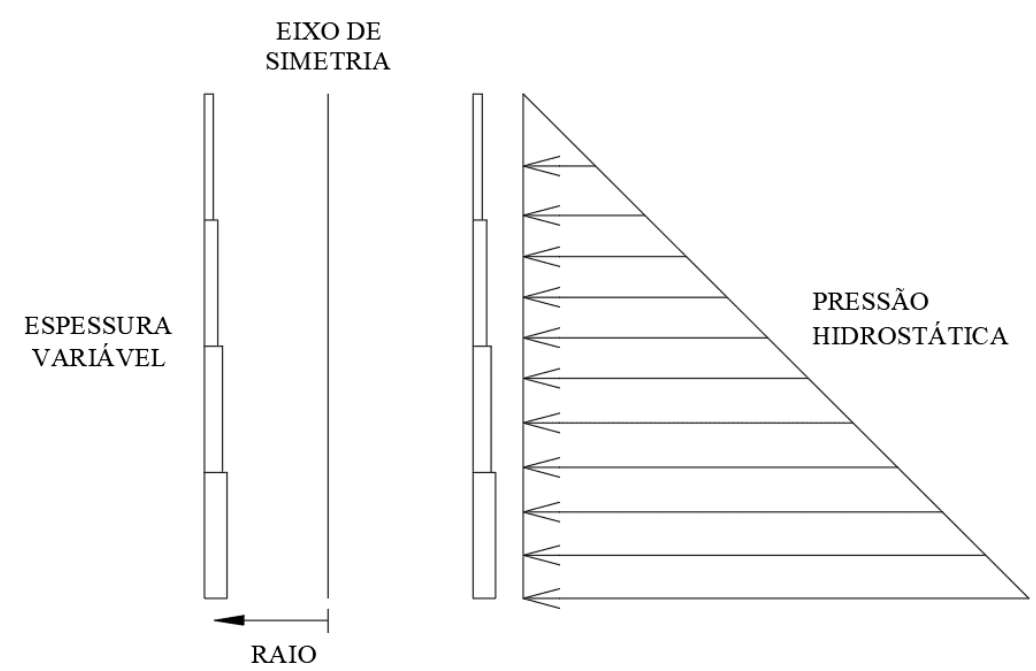

Fonte: O próprio autor

O fluxo de cálculo das espessuras das virolas dos tanques soldados sega o diagrama mostrado na figura 5 .

Figura 5 - Diagrama de fluxo do cálculo das espessuras das virolas dos tanques

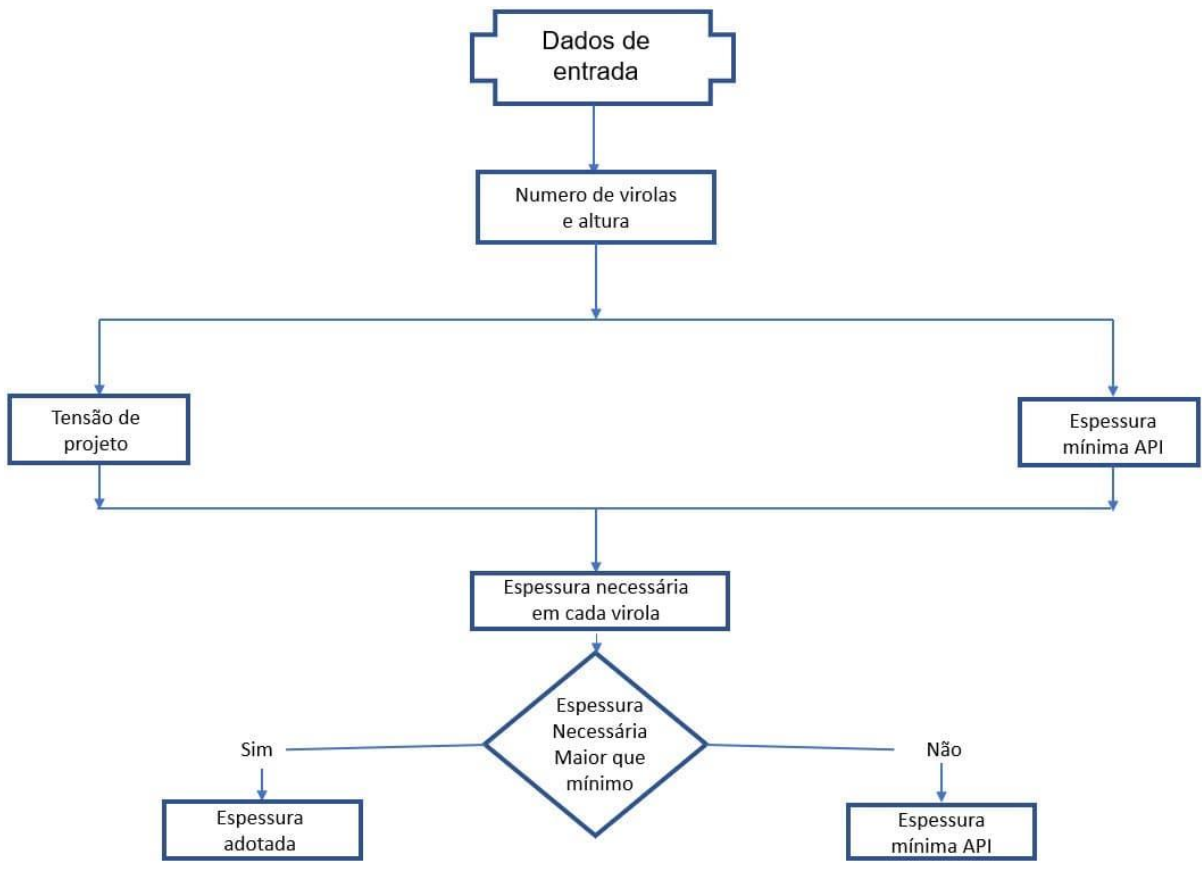

Fonte: O próprio autor

RC: 50072

Disponível em: https://www.nucleodoconhecimento.com.br/engenharia-civil/tanque-metalico 
Os pesos dos 7 tanques propostos neste trabalho foram apurados em duas etapas. A primeira etapa foi calculada o peso dos fundos dos reservatórios, considerando fundos com chapas anulares (Figura 6), de acordo com o item 5.4.1 da API 650 (Botton Plates), que prescreve a espessura mínima de $6,00 \mathrm{~mm}$ (1/4"). Foi considerado no peso dos fundos dos reservatórios a sobreposição de chapas em torno de 2,26\%.

Figura 6 - Disposição típica de chapas de fundo com chapas anulares.

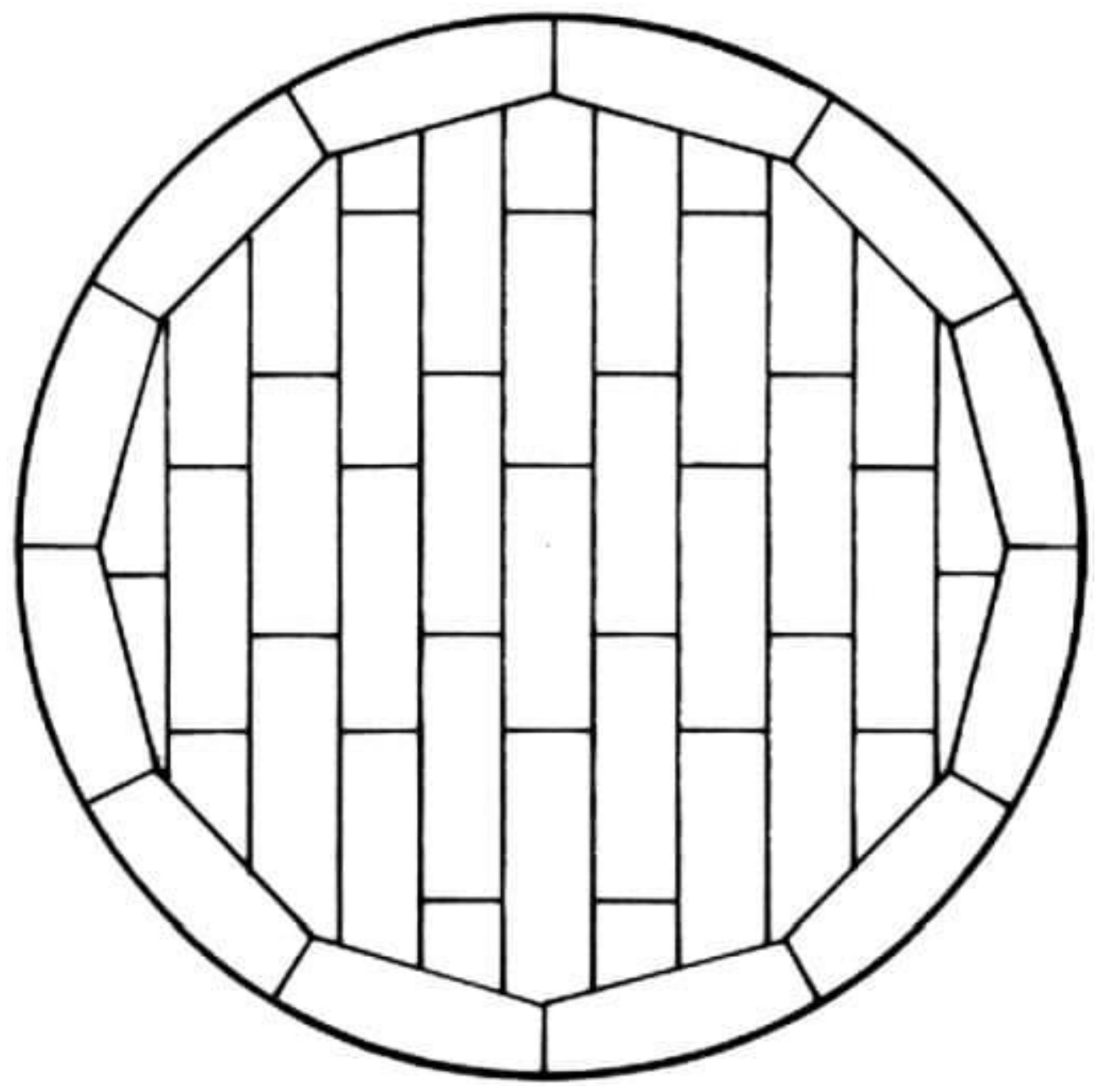

Fonte: ABNT NBR 7821 (1983)

Foram também considerados os pesos dos perfis tipo cantoneiras do reforço de borda superior, conforme especificado na Tabela 4 prescrita no item 5.1.5.9 - Roof and TopAngle Joints" da API 650, sobreposta ao último anel (virola) do costado, com aba horizontal voltada para o lado externo do tanque. 
Tabela 4 -Reforço de borda superior do costado.

\begin{tabular}{|c|c|c|}
\hline $\begin{array}{c}\text { Tank Diameter } \\
(D)\end{array}$ & $\begin{array}{c}\text { Minimum Top Angle Size } \\
\text { (in.) }\end{array}$ & $\begin{array}{c}\text { Minimum Top Angle Size } \\
(\mathrm{mm})\end{array}$ \\
\hline$D \leq 11 \mathrm{~m},(D \leq 35 \mathrm{ft})$ & $2 \times 2 \times 3 / 16$ & $51 \times 51 \times 4.8$ \\
\hline $11 \mathrm{~m}<D \leq 18 \mathrm{~m},(35 \mathrm{ft}<D \leq 60 \mathrm{ft})$ & $2 \times 2 \times 1 / 4$ & $51 \times 51 \times 6.4$ \\
\hline$D>18 \mathrm{~m},(D>60 \mathrm{ft})$ & $3 \times 3 \times 3 / 8$ & $76 \times 76 \times 9.5$ \\
\hline
\end{tabular}

Fonte: API 650 (2007)

O peso dos costados foi apurado após a determinação da espessura de cada chapa que compõe as virolas dos tanques para cada relação de H/D, considerando-se as espessuras calculadas apenas com a equação $1 \mathrm{e}$ as espessuras considerando as espessuras mínimas prescritas pela API 650 (Tabela 5). Utilizou-se o método de um pé (1FM), com eficiência de soldagem de $1,00(100 \%)$ e sem consideração de sobrespessura de corrosão e não foi aplicado as forças decorrentes da ação de ventos. As espessuras utilizadas para os dimensionamentos das virolas foram (em milímetros): 2,00; 2,25; 2,65; 3,00; 3,35; 3,75; 4,25; 4,75 e 6,35, todas com largura de $1.500,00 \mathrm{~mm}$.

Tabela 5 - Espessuras das chapas dos costados e pesos dos tanques estudados.

\begin{tabular}{|c|c|c|c|c|c|c|c|c|c|c|c|c|c|c|c|c|c|c|c|c|c|}
\hline \multicolumn{2}{|c|}{ Chapas dos costados } & \multirow{2}{*}{\multicolumn{16}{|c|}{ Virolas }} & \multirow{2}{*}{\multicolumn{3}{|c|}{ Peso (kg) }} & \multirow[t]{2}{*}{ Peso $/ \mathrm{m}^{3}$} \\
\hline$H / D$ & Espessuras & v1 & V2 & $V_{3}$ & v4 & v5 & v6 & $v 7$ & V8 & v9 & V10 & V11 & V12 & & & & V16 & & & Total & \\
\hline \multirow{2}{*}{4,00} & \begin{tabular}{|c|} 
Cálculo \\
adotado \\
\end{tabular} & $\begin{array}{l}1,86 \\
200\end{array}$ & $\begin{array}{l}1,05 \\
200\end{array}$ & $\begin{array}{l}0.24 \\
200\end{array}$ & & & & & & & & & & & & & & $2.770,74$ & \multirow{2}{*}{$8.984,72$} & $11.755,46$ & 17,81 \\
\hline & Esp. Minima & 4,75 & 4,75 & 4,75 & & & & & & & & & & & & & & $6.580,95$ & & $15.565,67$ & 23,58 \\
\hline \multirow{2}{*}{3,00} & \begin{tabular}{|c|} 
Cálculo \\
adotado \\
\end{tabular} & $\begin{array}{l}2.08 \\
2.25\end{array}$ & $\begin{array}{l}1.34 \\
2.00\end{array}$ & $\begin{array}{l}0.61 \\
2.00\end{array}$ & & & & & & & & & & & & & & $3.682,22$ & \multirow{2}{*}{$7.416,57$} & $11.098,79$ & 16,82 \\
\hline & Esp. Minima & 4,75 & 4,75 & 4,75 & & & & & & & & & & & & & & $7.238,63$ & & $14.655,20$ & 22,20 \\
\hline \multirow{2}{*}{2,00} & \begin{tabular}{|c|} 
Cálculo \\
adotado \\
\end{tabular} & \begin{tabular}{r|}
2.42 \\
2.65 \\
\end{tabular} & $\begin{array}{l}1,77 \\
2.00 \\
\end{array}$ & \begin{tabular}{|l|}
1,13 \\
2.00
\end{tabular} & $\begin{array}{l}0.49 \\
2.00 \\
\end{array}$ & & & & & & & & & & & & & $3.769,27$ & \multirow{2}{*}{$5.660,31$} & $9.429,58$ & 16,82 \\
\hline & Esp. Minima & 4,75 & 4,75 & 4,75 & 4,75 & & & & & & & & & & & & & $8.273,91$ & & $13.934,22$ & 21,11 \\
\hline \multirow{2}{*}{1,50} & \begin{tabular}{|c|} 
Cálculo \\
adotado \\
\end{tabular} & $\begin{array}{l}, 68 \\
3,00 \\
\end{array}$ & $\begin{array}{l}2,10 \\
2,25 \\
\end{array}$ & \begin{tabular}{|l|}
1,52 \\
2,00 \\
\end{tabular} & $\begin{array}{l}0.93 \\
2.00 \\
\end{array}$ & $\begin{array}{l}0,35 \\
2,00 \\
\end{array}$ & & & & & & & & & & & & $4.334,43$ & \multirow{2}{*}{$4.670,28$} & $9.004,71$ & 13,64 \\
\hline & Esp. Minima & 4,75 & 4,75 & 4,75 & 4,75 & 4,75 & & & & & & & & & & & & $9.109,58$ & & $13.779,86$ & 20,88 \\
\hline \multirow[t]{2}{*}{1,00} & \begin{tabular}{|c|} 
Cálculo \\
adotado \\
\end{tabular} & $\begin{array}{l}3.10 \\
3,35 \\
\end{array}$ & $\begin{array}{l}2,59 \\
2,65\end{array}$ & \begin{tabular}{|l|l|}
2.08 \\
2.25
\end{tabular} & $\begin{array}{l}1.57 \\
2.00\end{array}$ & $\begin{array}{l}1,06 \\
2,00\end{array}$ & $\begin{array}{l}0,55 \\
2,00 \\
\end{array}$ & \begin{tabular}{l|}
0,04 \\
2,00
\end{tabular} & & & & & & & & & & $4.891,92$ & \multirow[t]{2}{*}{$3.575,74$} & $8.467,66$ & 12,83 \\
\hline & Esp. Minima & 4.75 & 4.75 & 4.75 & 4.75 & 4.75 & 4.75 & 4.75 & & & & & & & & & & $10.417,55$ & & $13.993,29$ & 21,20 \\
\hline \multirow{2}{*}{0,50} & \begin{tabular}{|c|} 
Cálculo \\
adotado \\
\end{tabular} & $\begin{array}{l}3.96 \\
4.25 \\
\end{array}$ & $\begin{array}{l}3,56 \\
3.75 \\
\end{array}$ & \begin{tabular}{l|}
3,15 \\
3.35 \\
\end{tabular} & $\begin{array}{l}2.75 \\
3.00 \\
\end{array}$ & $\begin{array}{l}2,34 \\
2,65 \\
\end{array}$ & $\begin{array}{l}1,94 \\
2,00 \\
\end{array}$ & $\begin{array}{l}1,53 \\
2,00 \\
\end{array}$ & $\begin{array}{l}1,13 \\
2.00 \\
\end{array}$ & $\begin{array}{l}0,72 \\
2.00 \\
\end{array}$ & $\begin{array}{l}0.32 \\
2.00 \\
\end{array}$ & & & & & & & $7.475,74$ & \multirow{2}{*}{$2.246,18$} & $9.721,92$ & 14,73 \\
\hline & Esp. Minima & 4,75 & 4,75 & 4,75 & 4,75 & 4,75 & 4,75 & 4,75 & 4,75 & 4,75 & 4,75 & & & & & & & $13.144,25$ & & $15.390,43$ & 23,32 \\
\hline \multirow{2}{*}{0,25} & \begin{tabular}{|l|} 
Cálculo \\
adotado
\end{tabular} & $\begin{array}{l}5,03 \\
6,35 \\
\end{array}$ & $\begin{array}{r}4,70 \\
4,75 \\
\end{array}$ & \begin{tabular}{|l|}
4,38 \\
475
\end{tabular} & $\begin{array}{l}4.06 \\
4.25\end{array}$ & \begin{tabular}{|l|}
3,74 \\
3,75
\end{tabular} & \begin{tabular}{|l|}
3,42 \\
3,75
\end{tabular} & \begin{tabular}{|l|}
3,10 \\
3,35
\end{tabular} & $\begin{array}{l}2,78 \\
300\end{array}$ & \begin{tabular}{l|l|}
2,46 \\
2,65
\end{tabular} & $\begin{array}{l}2,13 \\
2,25\end{array}$ & $\begin{array}{l}1,81 \\
2,00\end{array}$ & $\begin{array}{l}1,49 \\
2,00\end{array}$ & $\begin{array}{l}1,17 \\
2,00\end{array}$ & \begin{tabular}{|l|}
0,85 \\
2,00
\end{tabular} & $\begin{array}{l}0,53 \\
2,00\end{array}$ & $\begin{array}{l}0,21 \\
2,00\end{array}$ & $12.572,65$ & \multirow{2}{*}{$1.412,66$} & $13.985,31$ & 21,19 \\
\hline & \begin{tabular}{|l|} 
Esp. Minima \\
\end{tabular} & 6,35 & 4,75 & 4,75 & 4,75 & 4,75 & 4,75 & 4,75 & 4,75 & 4,75 & 4,75 & 4,75 & 4,75 & 4,75 & 4,75 & 4,75 & 4,75 & $17.240,36$ & & $18.653,02$ & 28,26 \\
\hline
\end{tabular}

Fonte: O próprio autor

\section{ANÁLISE PELO MÉTODO DOS ELEMENTOS FINITOS}

Para a análise pelo método dos elementos finitos MEF) dos 7 tanques com capacidade de $660,00 \mathrm{~m}^{3}$ e dimensões descritas na Tabela 2, foi utilizado o software AUTODESK

Disponível em: https://www.nucleodoconhecimento.com.br/engenharia-civil/tanque-metalico 
SIMULATION MECHANICAL 2018, com discretização da malha em $150 \times 150 \mathrm{~mm}$ (Figuras 7 e 8 ).

Figura 7 - Discretização do reservatório H/D 1,00 - diâmetro e altura 9,43m.

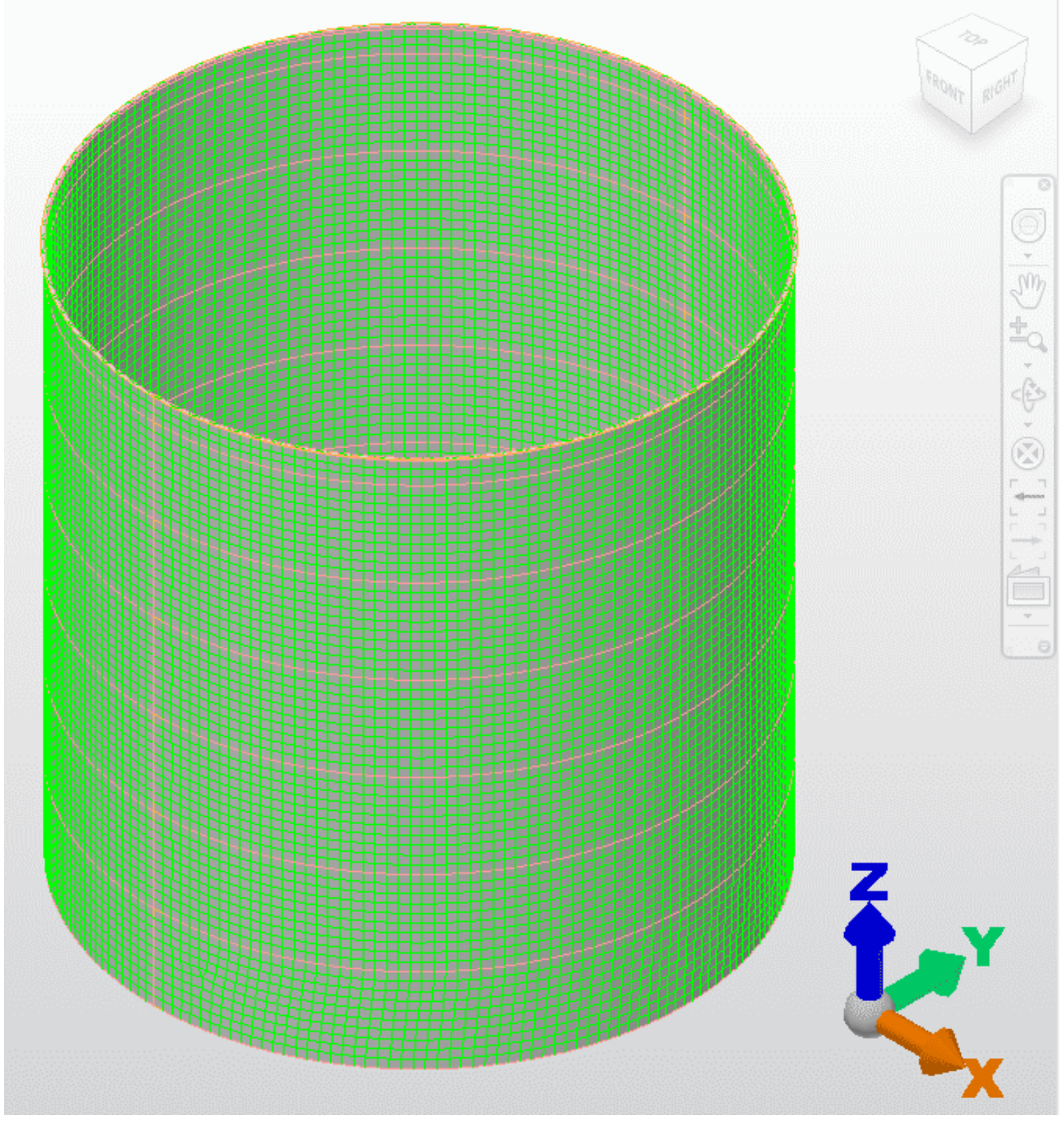

Fonte: O próprio autor 
Figura 8 - Aplicação do carregamento de água reservatório H/D 1,00

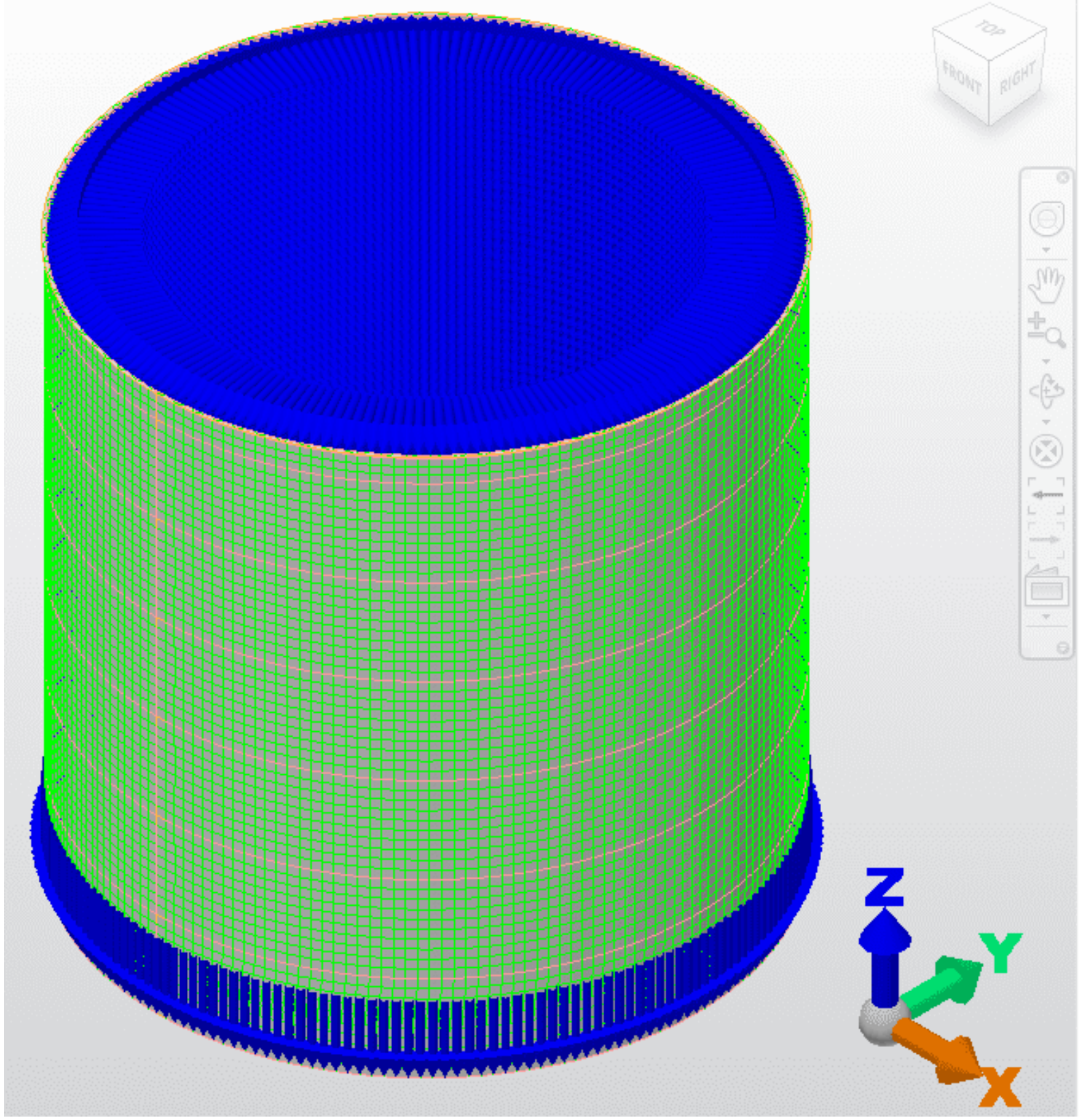

Fonte: O próprio autor

\section{RESULTADOS}

Segue os resultados da análise através dos métodos dos elementos finitos - MEF, dos 7 tanques propostos, com a utilização do software AUTODESK SIMULATION MECHANICAL 2018

RC: 50072

Disponível em: https://www.nucleodoconhecimento.com.br/engenharia-civil/tanque-metalico 


\subsection{TANQUE H/D = 4,00 - DIÂMETR014,98 M E ALTURA 3,75 M}

As figuras 9 e 10 apresenta as tensões circunferenciais com as espessuras do tanque calculadas de acordo com a Equação 1 e assumidas como 2,00 mm. A máxima tensão da virola 1 foi de 147,81 Mpa, menor que a tensão admissível do aço ASTM A36, de 160,00 Mpa, de acordo com a tabela 5-2 da API 650.

Figura 9 - Tensões circunferenciais H/D 4,00 em 3D - espessuras calculadas

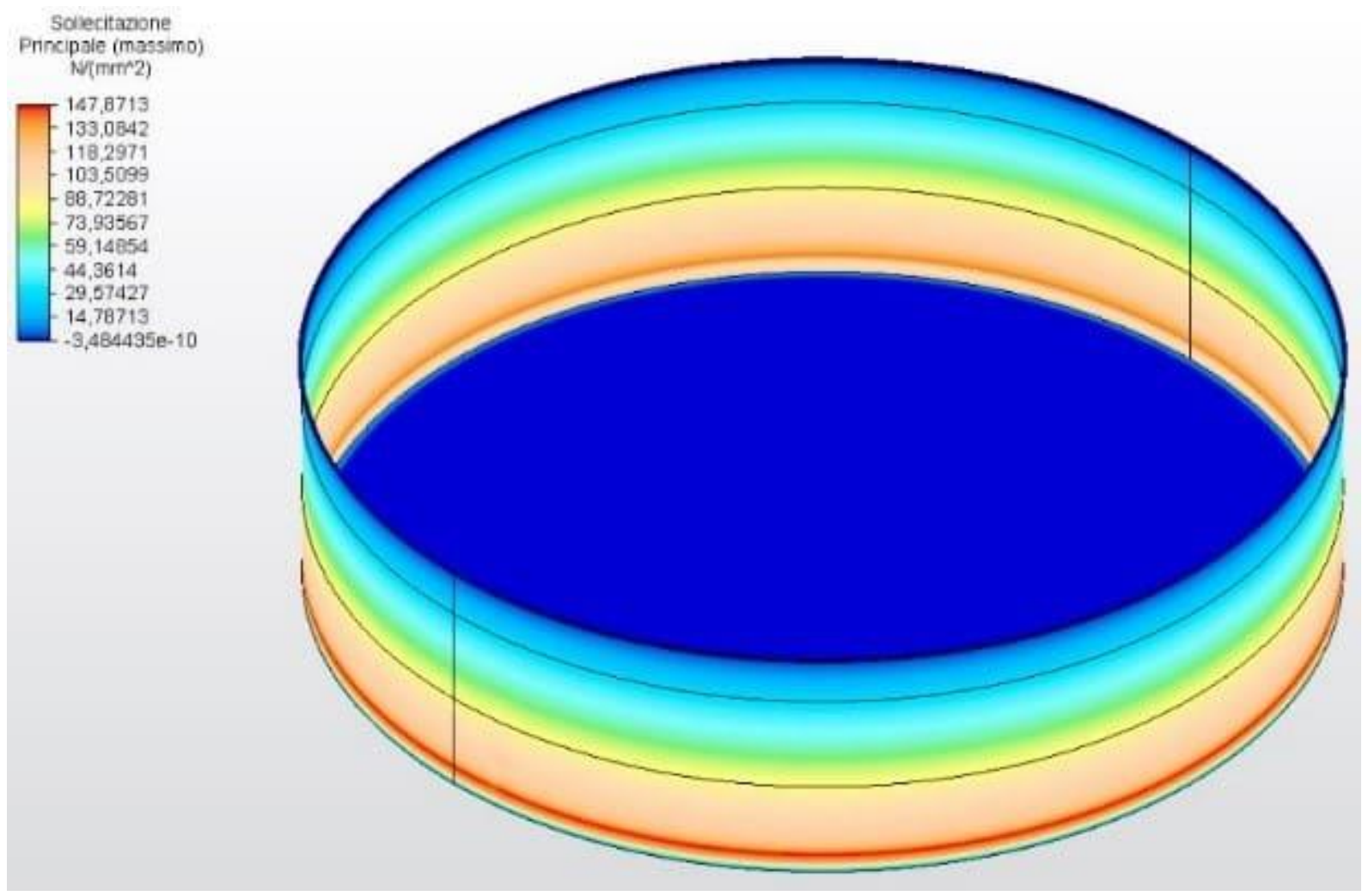

Fonte: O próprio autor 
Figura 10 - Tensões circunferenciais H/D 4,00 em 2D - espessuras calculadas

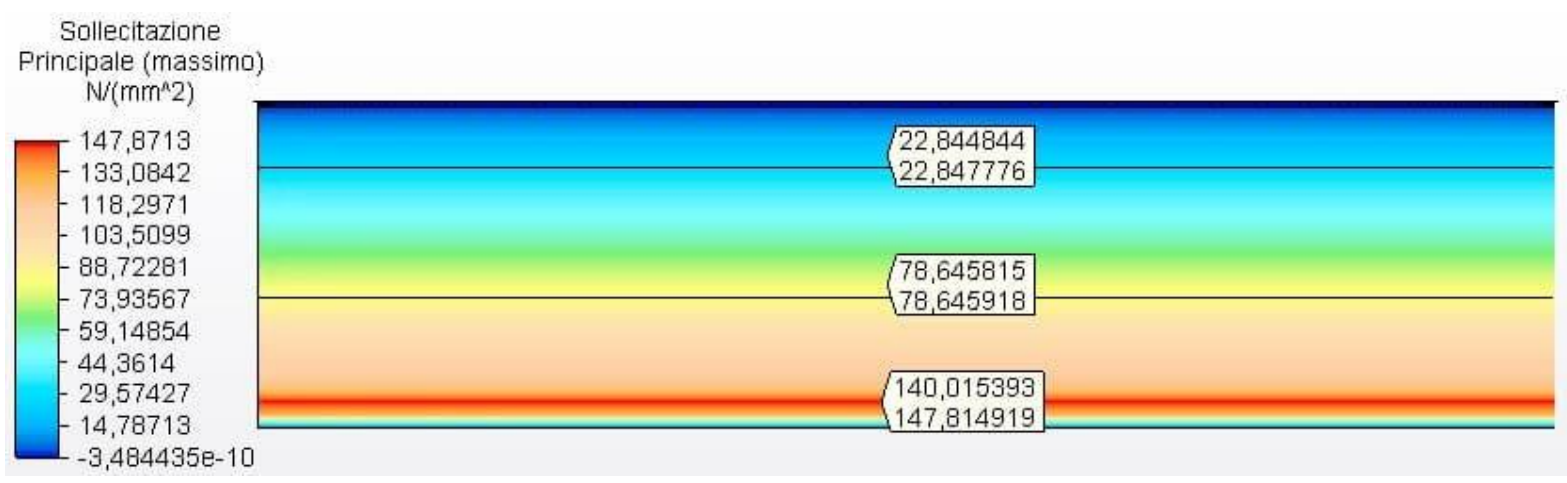

Fonte: O próprio autor

A figura 11 apresenta as tensões circunferenciais com as espessuras do tanque calculadas de acordo com as espessuras mínimas da API 650, no caso 4,75 mm. Tensão máxima foi de 60,27 MPa.

Figura 11 - Tensões circunferenciais H/D 4,00 em 2D- espessuras minimas

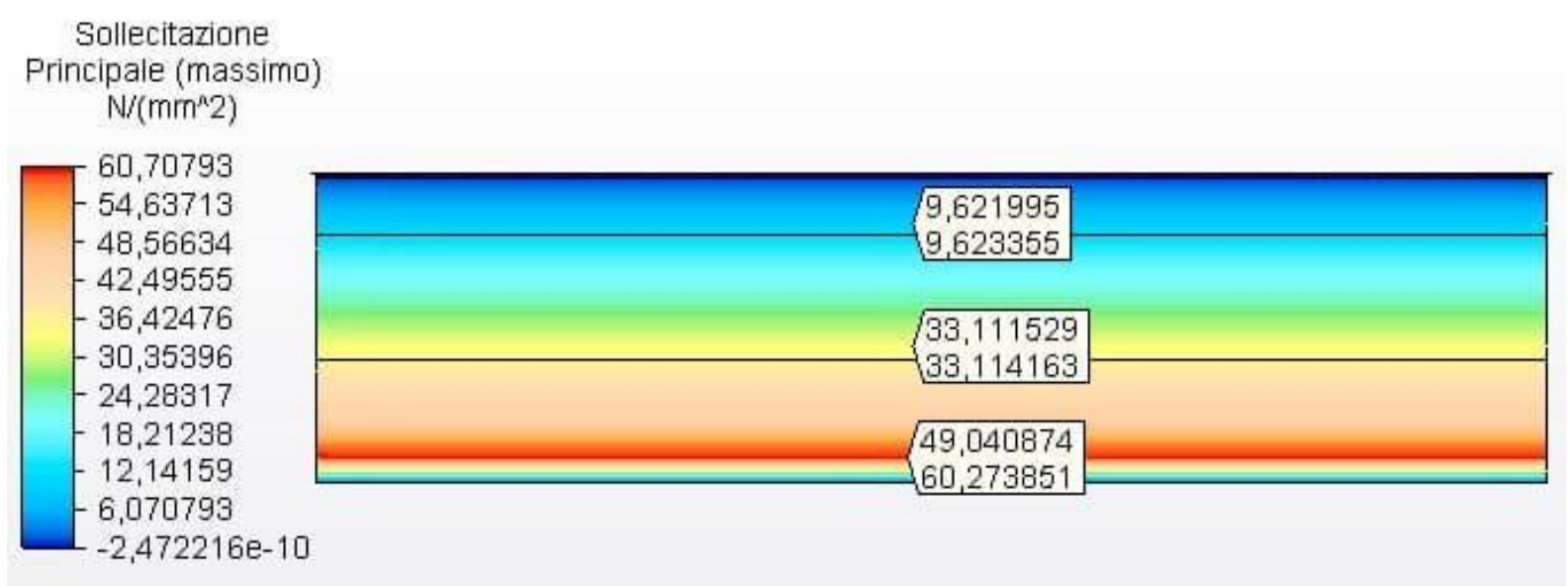

Fonte: O próprio autor

A figura 12 mostra as curvas de tensões circunferenciais, em função das espessuras das virolas e altura de carregamento de água. 
Figura 12 - Curvas das tensões circunferências do tanque H/D 4,00

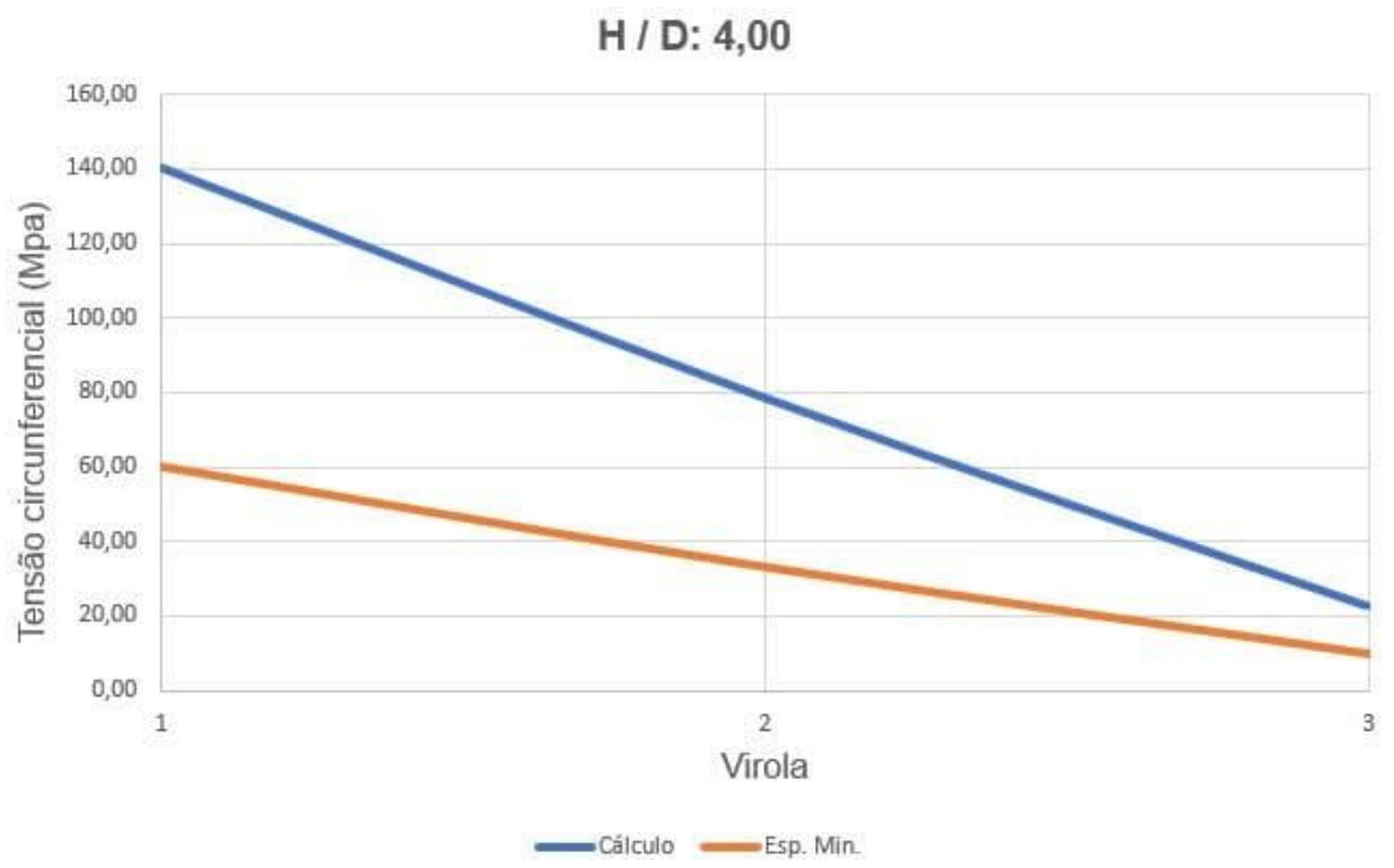

Fonte: O próprio autor

\subsection{TANQUE H/D = 3,00 - DIÂMETRO 13,61 M E ALTURA 4,54 M}

As figuras 13 e 14 apresenta as tensões circunferenciais com as espessuras do tanque calculadas de acordo com a Equação 1 e assumidas como a virola 1 com 2,25 $\mathrm{mm}$ e as demais com 2,00 mm. A máxima tensão da virola 1 foi de 146,67 Mpa, menor que a tensão admissível do aço ASTM A36, de 160,00 Mpa, de acordo com a tabela 5-2 da API 650. 
Figura 13 - Tensões circunferenciais H/D 3,00 em 3D - espessuras calculadas

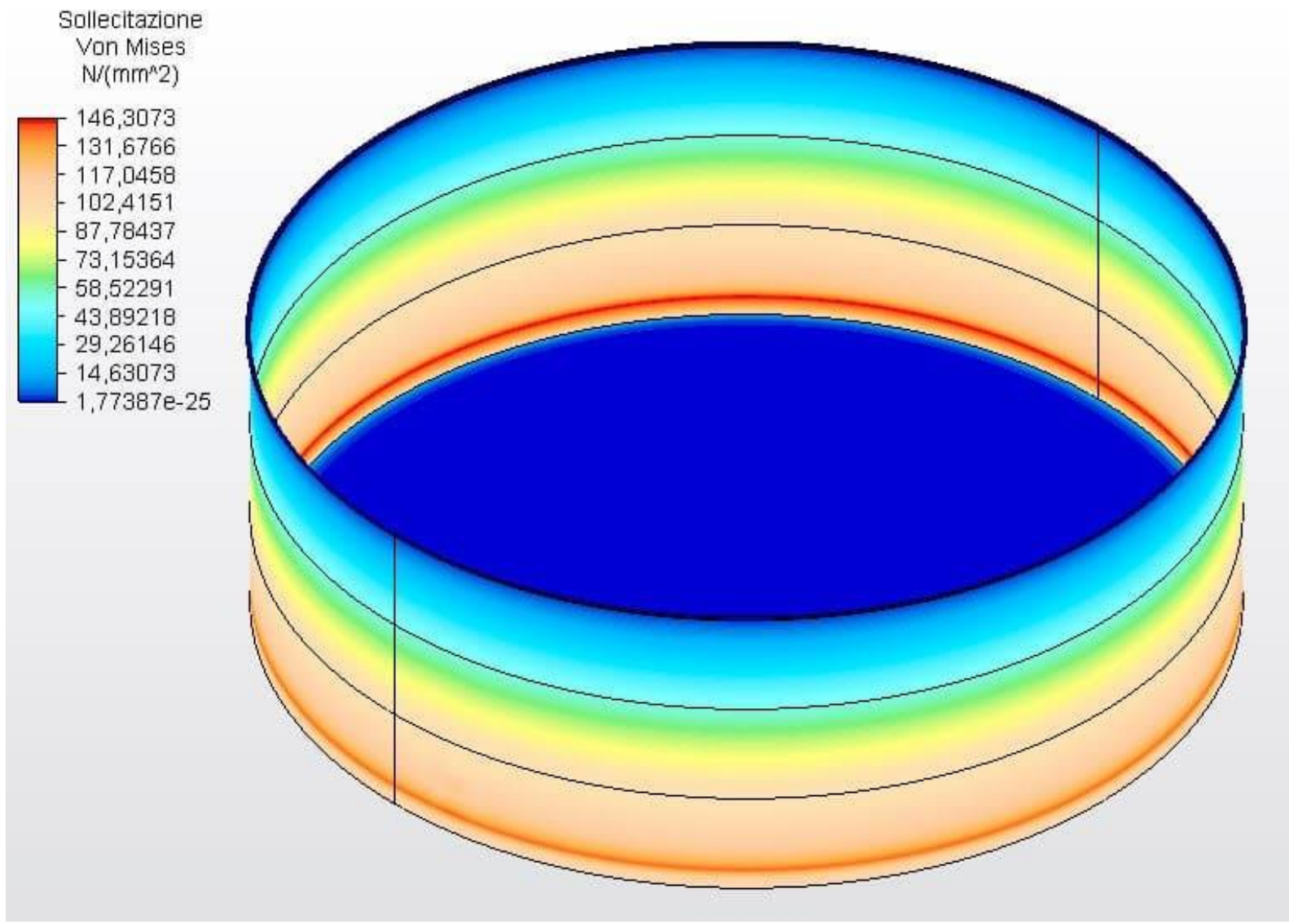

Fonte: O próprio autor

Figura 14 - Tensões circunferenciais H/D 3,00 em 2D - espessuras calculadas

Sollecitazione

Principale (massimo)

$\mathrm{N} /\left(\mathrm{mr} \mathrm{n}^{n} 2\right)$

$-147,1057$
$-132,3951$
$-117,6845$
$-102,974$
$-88,26339$
$-73,55283$
$-58,84226$
$-44,1317$
$-29,42113$
$-14,71057$
$-3,944926 \mathrm{e}-10$

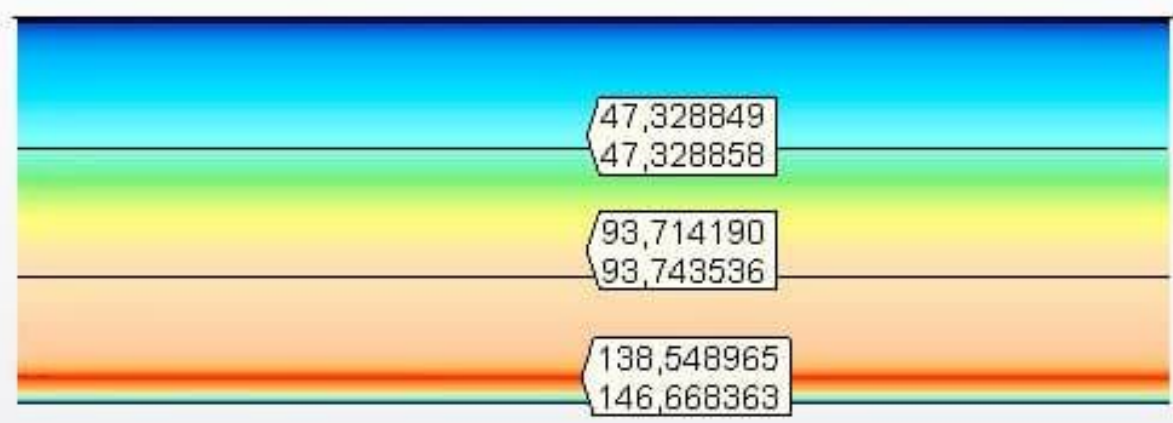

Fonte: O próprio autor

Disponível em: https://www.nucleodoconhecimento.com.br/engenharia-civil/tanque-metalico 
A figura 15 apresenta as tensões circunferenciais com as espessuras do tanque calculadas de acordo com as espessuras mínimas da API 650, no caso 4,75 mm. Tensão máxima foi de 68,17 MPa.

Figura 15 - Tensões circunferenciais H/D 3,00 em 2D- espessuras minimas

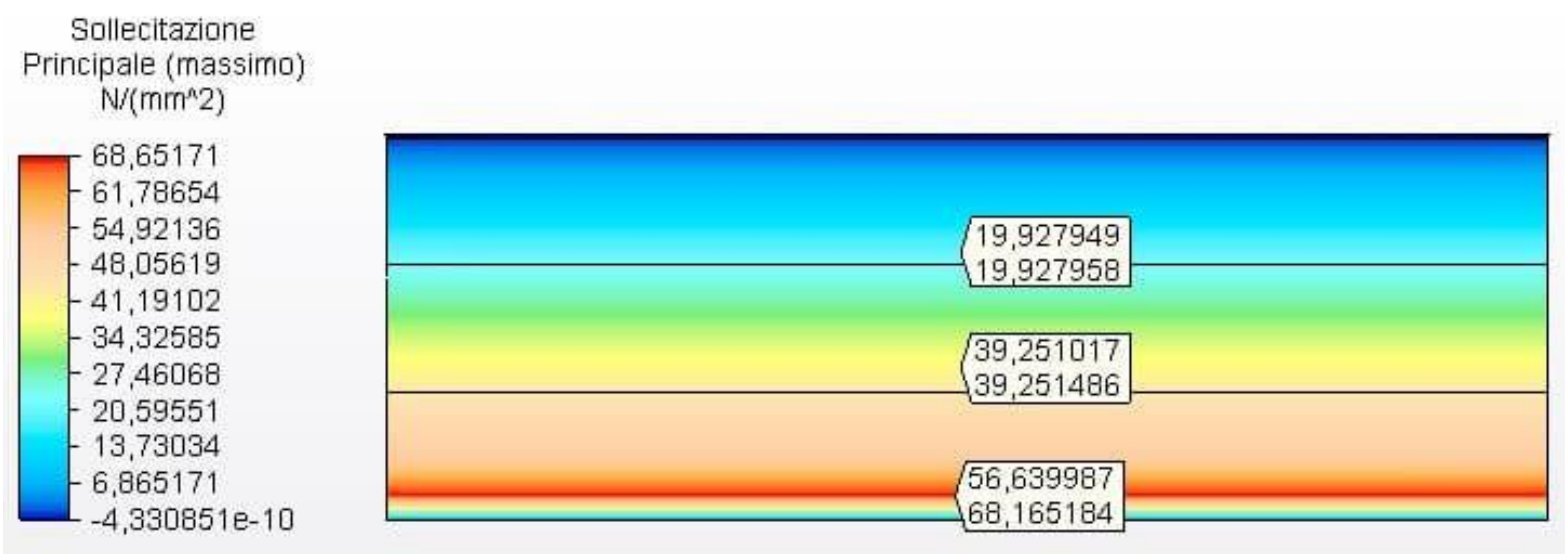

Fonte: O próprio autor

A figura 16 mostra as curvas de tensões circunferenciais, em função das espessuras das virolas e altura de carregamento de água.

Figura 16 - Curvas das tensões circunferenciais do tanque H/D 3,00

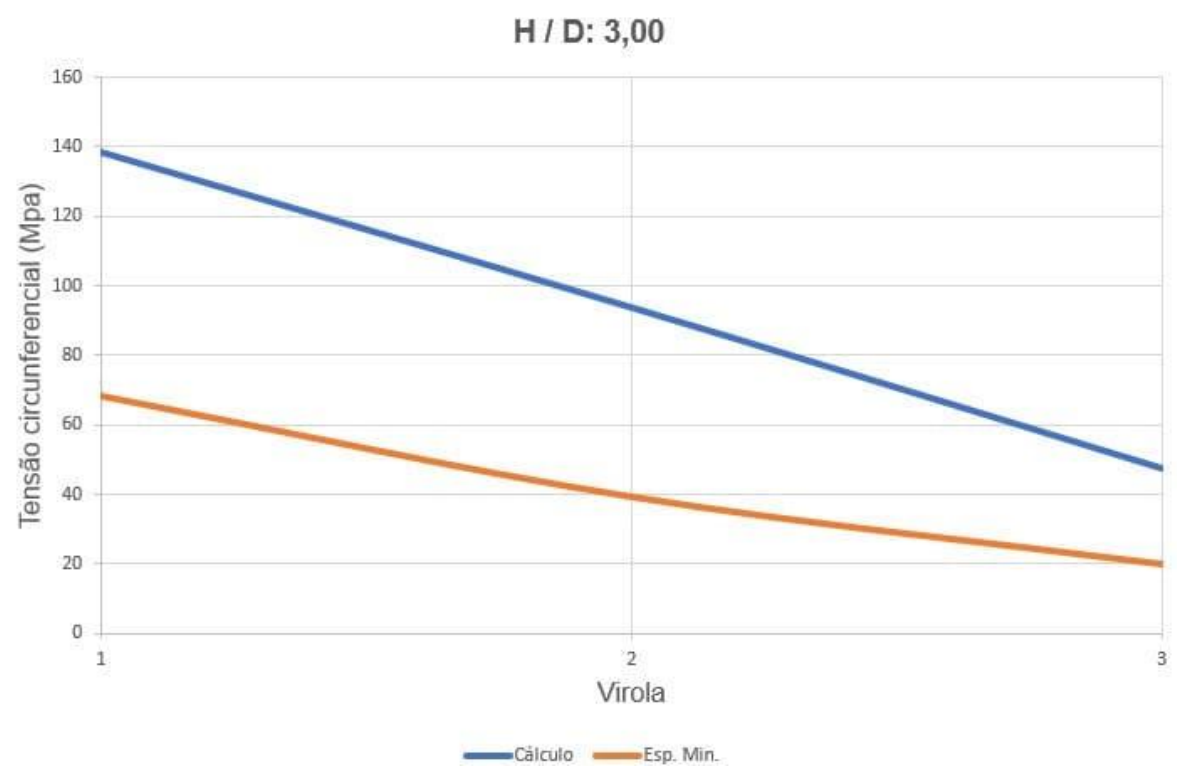

Fonte: O próprio autor

RC: 50072

Disponível em: https://www.nucleodoconhecimento.com.br/engenharia-civil/tanque-metalico 


\subsection{TANQUE H/D = 2,00 - DIÂMETRO 11,89 M E ALTURA 5,94 M}

As figuras 17 e 18 apresenta as tensões circunferenciais com as espessuras do tanque calculadas de acordo com a Equação 1 e assumidas como a virola 1 com 2,65 $\mathrm{mm}$ e as demais com 2,00 mm. A máxima tensão da virola 1 foi de 144,65 Mpa, menor que a tensão admissível do aço ASTM A36, de 160,00 Mpa, de acordo com a tabela 5-2 da API 650.

Figura 17 - Tensões circunferenciais H/D 2,00 em 3D - espessuras calculadas

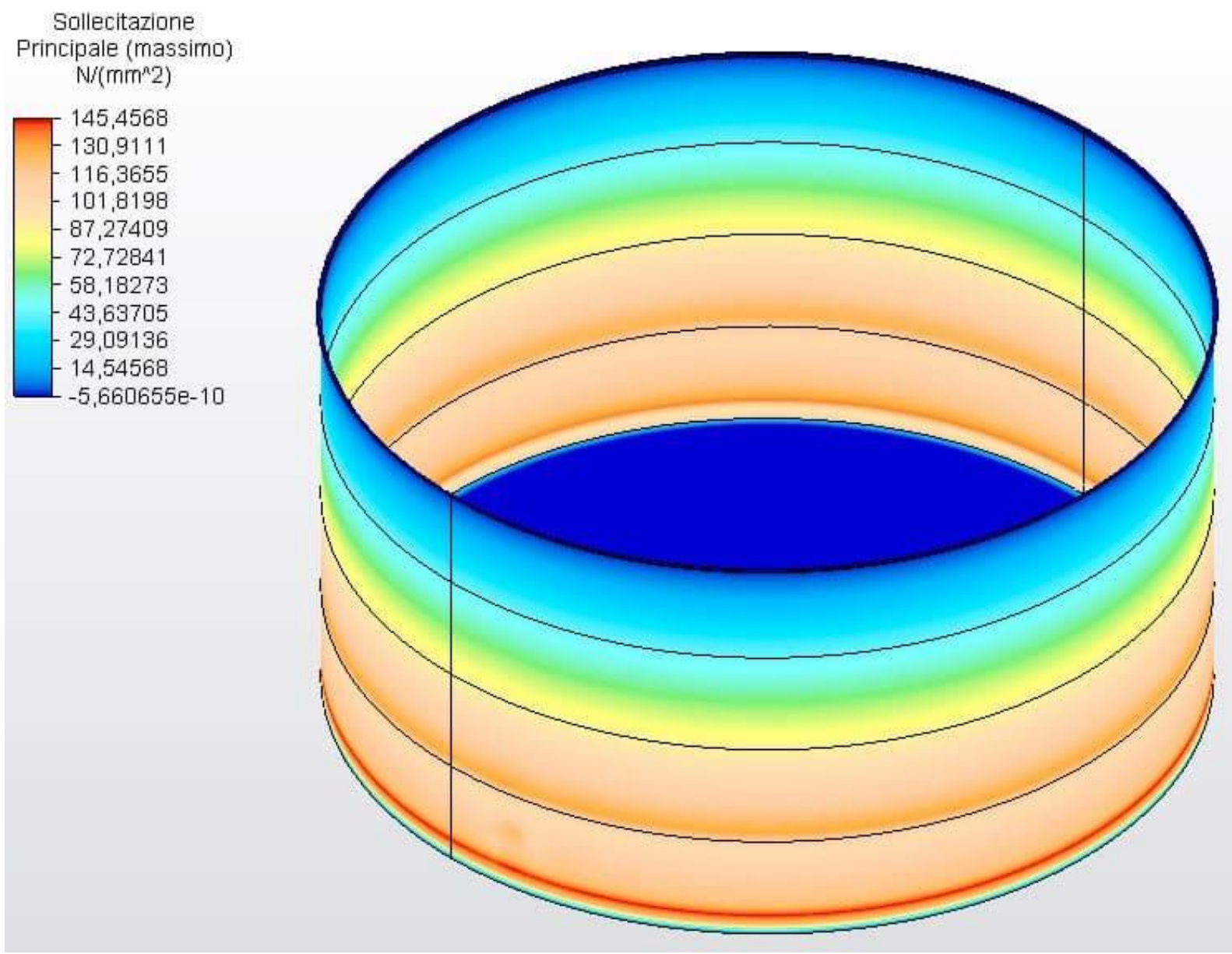

Fonte: O próprio autor 
Figura 18 - Tensões circunferenciais H/D 2,00 em 2D - espessuras calculadas

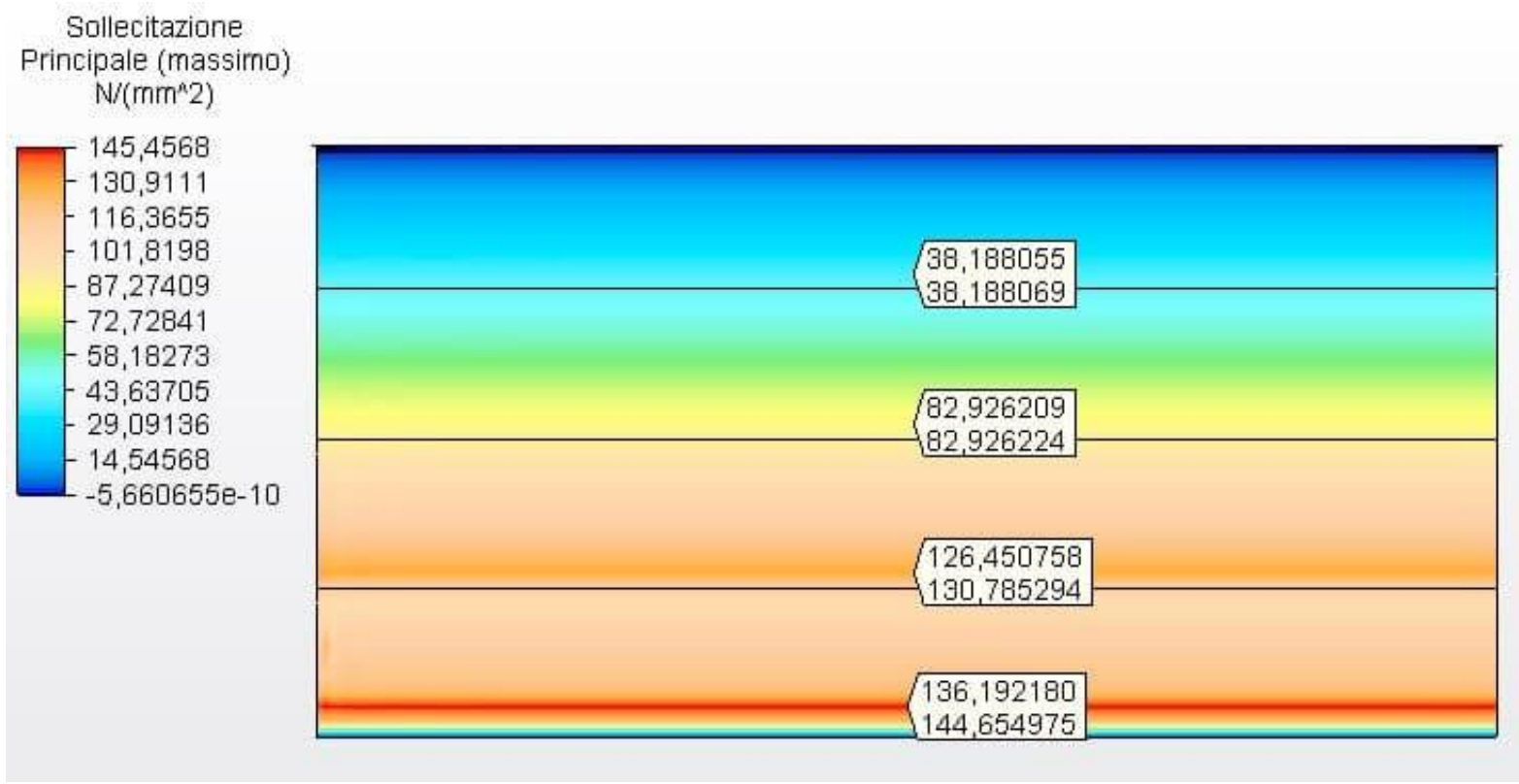

Fonte: O próprio autor

A figura 19 apresenta as tensões circunferenciais com as espessuras do tanque calculadas de acordo com as espessuras mínimas da API 650, no caso 4,75 mm. Tensão máxima foi de 80,26 MPa.

Figura 19 - Tensões circunferenciais H/D 2,00 em 2D- espessuras minimas

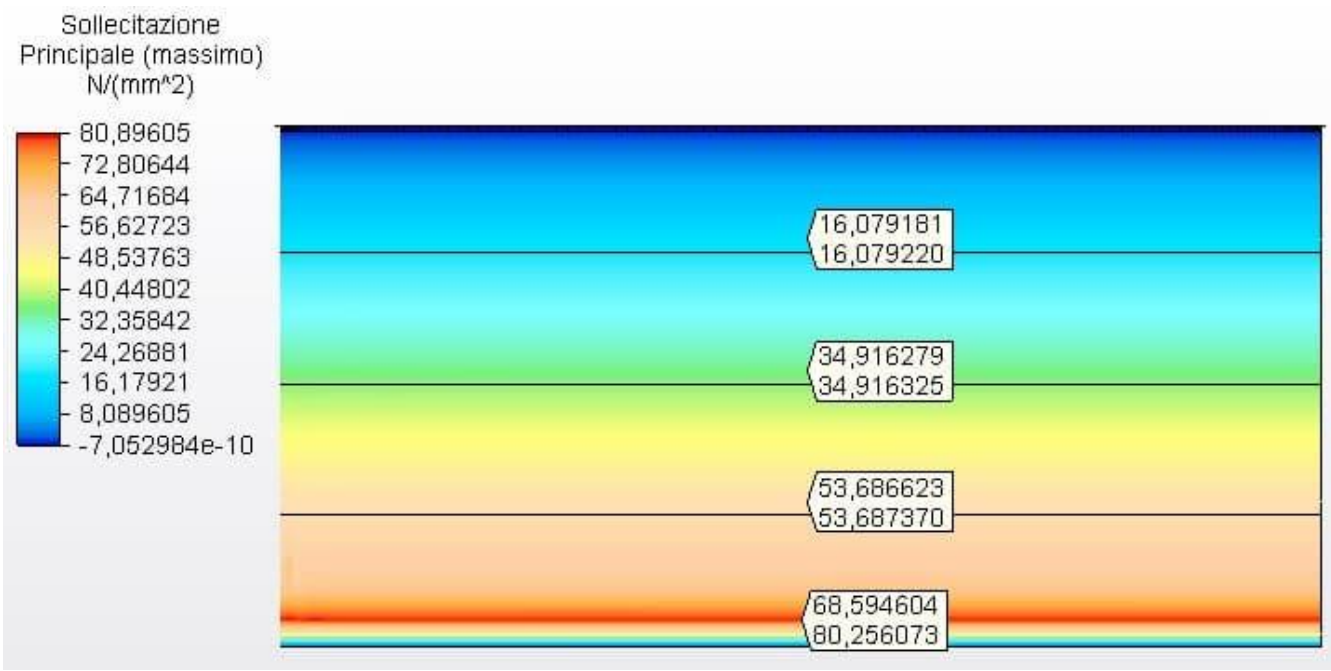

Fonte: O próprio autor

Disponível em: https://www.nucleodoconhecimento.com.br/engenharia-civil/tanque-metalico 
A figura 20 mostra as curvas de tensões circunferenciais, em função das espessuras das virolas e altura de carregamento de água.

Figura 20 - Curvas das tensões circunferenciais do tanque H/D 2,00

H / D: 2,0

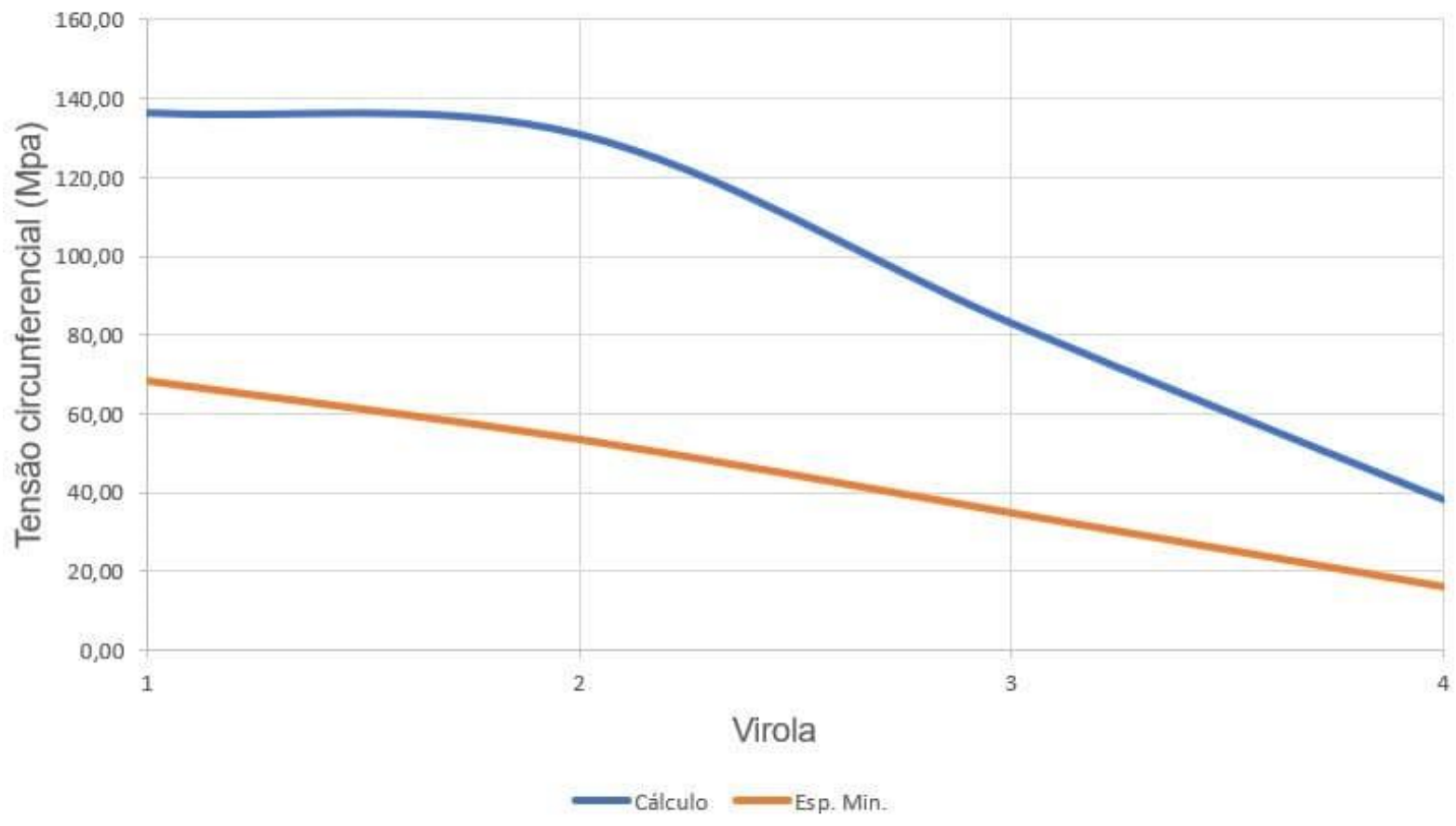

\subsection{TANQUE H/D = 1,00 - DIÂMETRO 9,43 M E ALTURA 9,43 M}

As figuras 21 e 22 apresenta as tensões circunferenciais com as espessuras do tanque calculadas de acordo com a Equação 1 e assumidas como a virola 1 com 3,35 $\mathrm{mm}$, virola 2 com 2,65 mm, virola 3 com 2,25 mm e as demais com 2,00 mm. A máxima tensão da virola 1 foi de 146,39 Mpa, menor que a tensão admissível do aço ASTM A36, de 160,00 Mpa, de acordo com a tabela 5-2 da API 650. 
Figura 21 - Tensões circunferenciais H/D 1,00 em 3D - espessuras calculadas

Sollecitazione Principale (massimo) $\mathrm{N} /\left(\mathrm{mm}^{n} 2\right)$

147,422

$-132,6798$

117,9376

$-103,1954$

$-88,45321$

$-73,71101$

$-58,96881$

$-44,22661$

29,4844

14,7422

$-1,464497 \mathrm{e}-09$

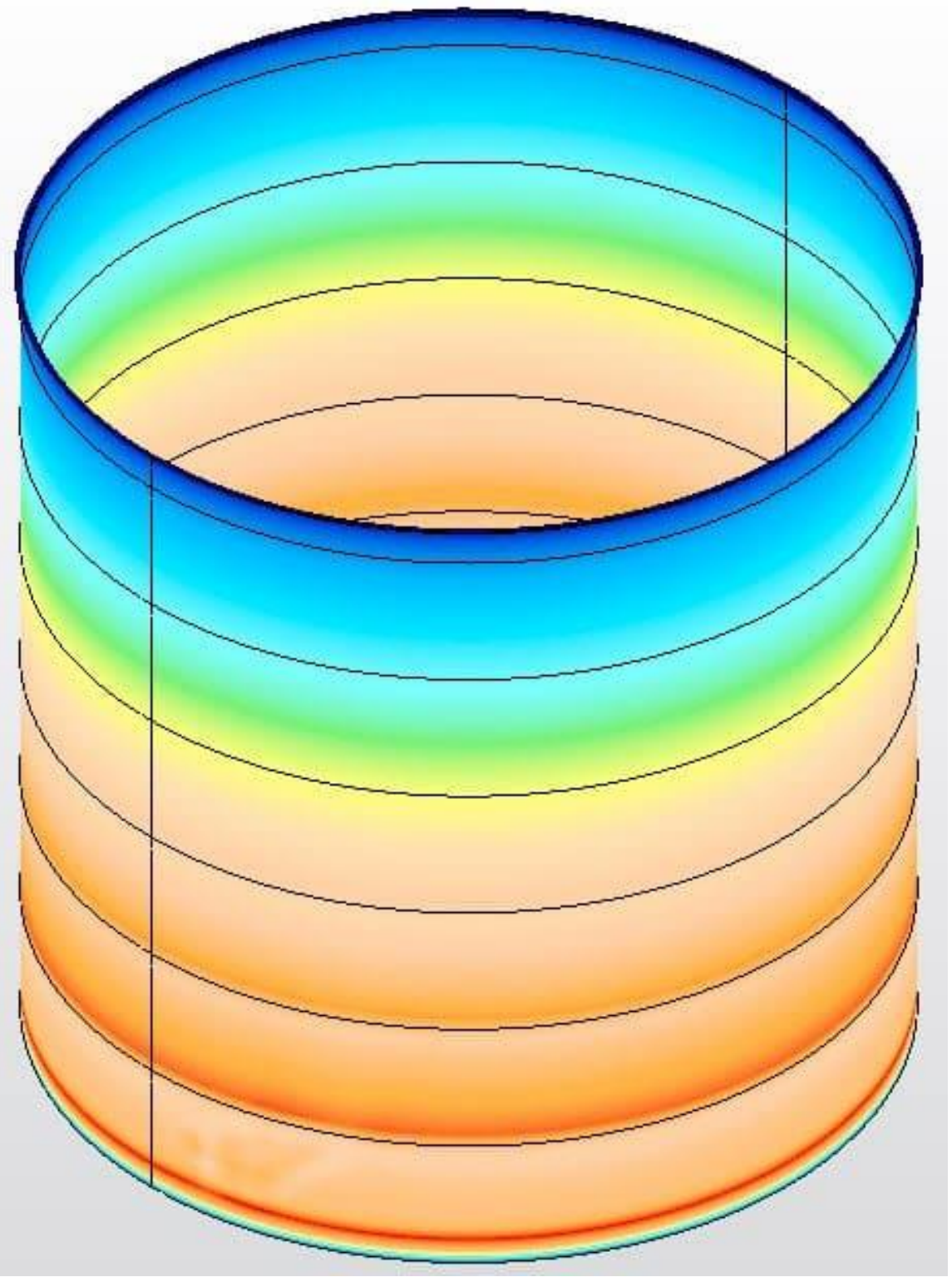

Fonte: O próprio autor 
Figura 22 - Tensões circunferenciais H/D 1,00 em 2D - espessuras calculadas

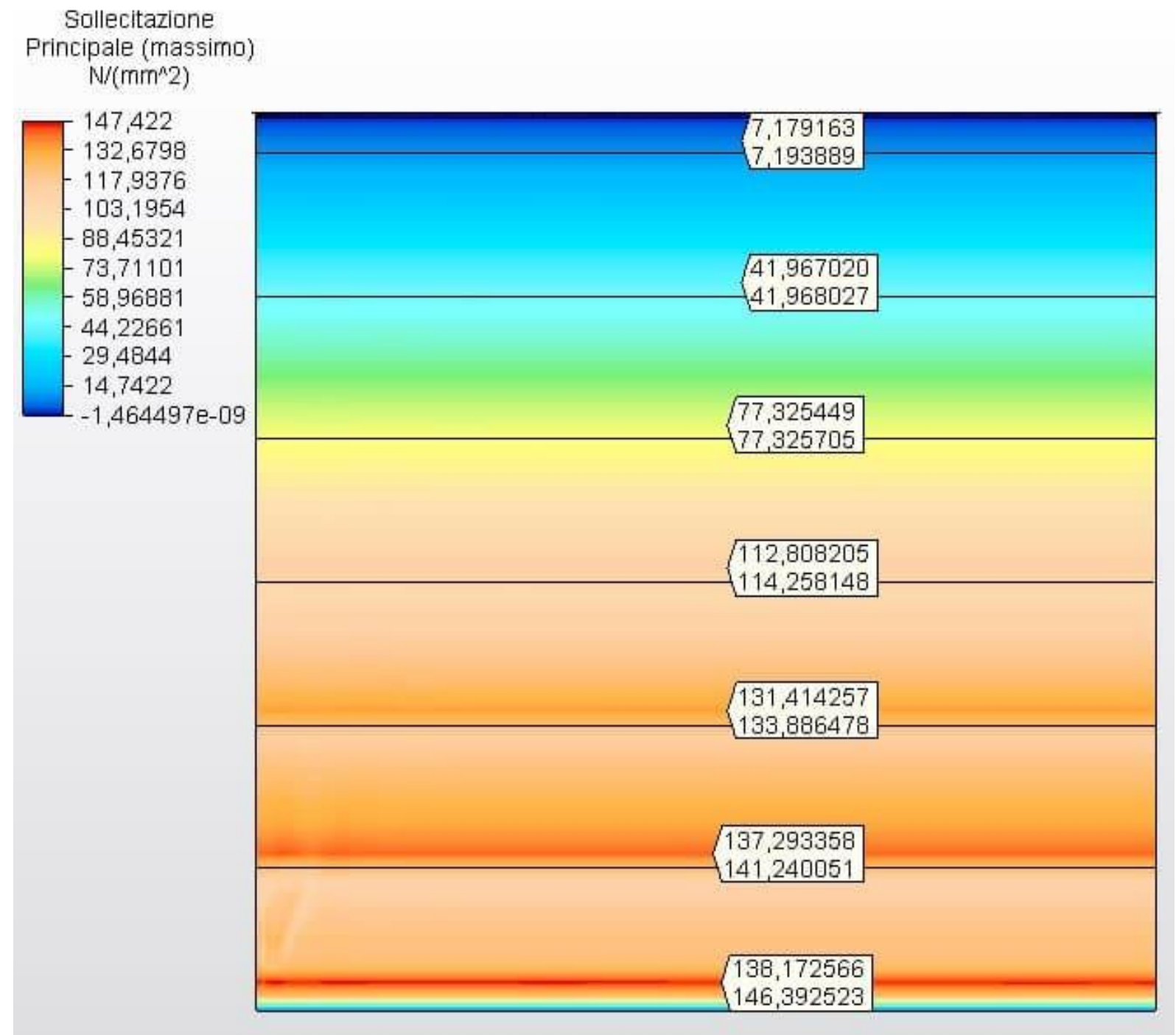

Fonte: O próprio autor

A figura 23 apresenta as tensões circunferenciais com as espessuras do tanque calculadas de acordo com as espessuras mínimas da API 650, no caso 4,75 mm. Tensão máxima foi de 104,02 MPa. 
Figura 23 - Tensões circunferenciais H/D 1,00 em 2D- espessuras minimas

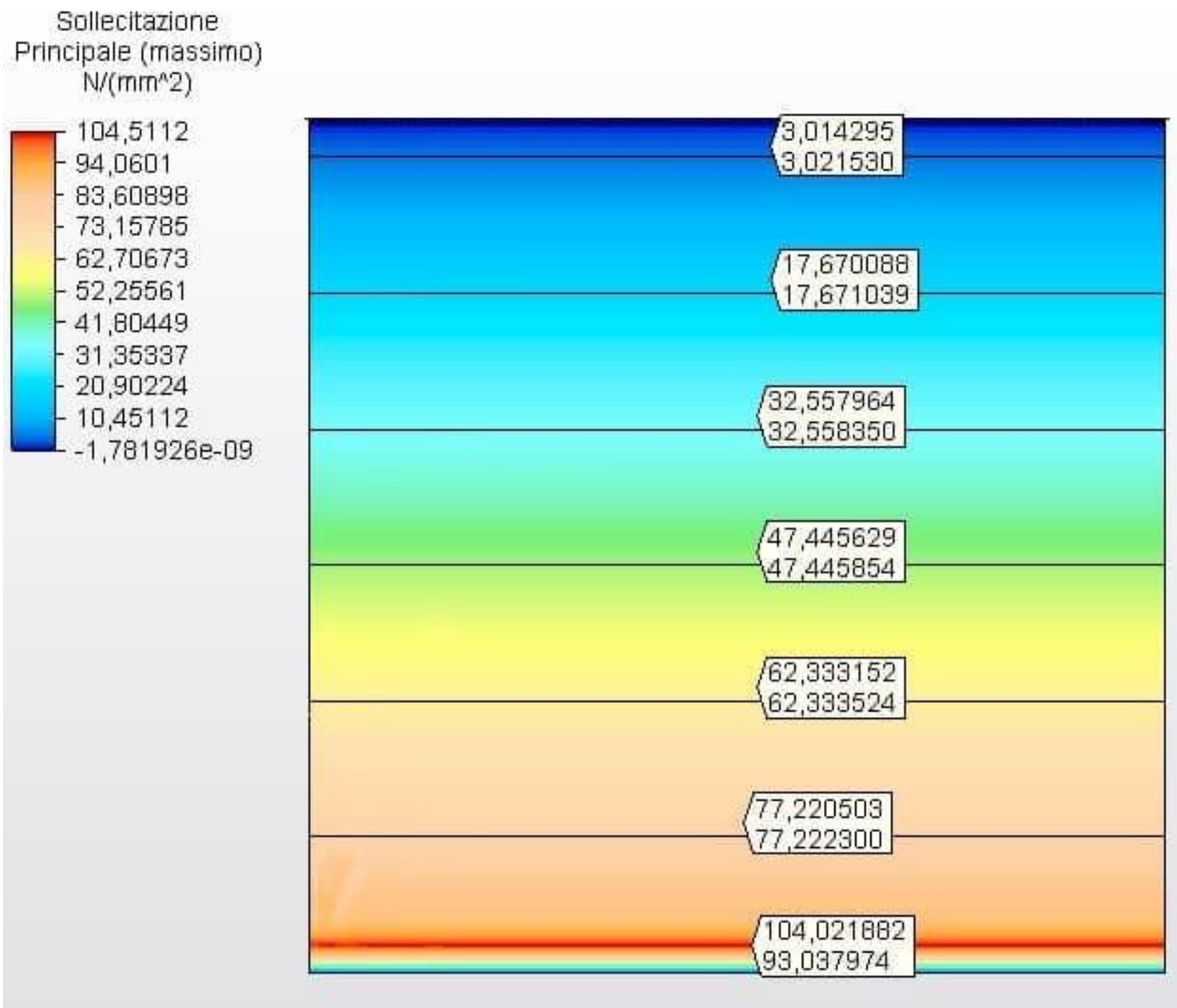

Fonte: O próprio autor

A figura 24 mostra as curvas de tensões circunferenciais, em função das espessuras das virolas e altura de carregamento de água. 
Figura 24 - Curvas das tensões circunferenciais do tanque H/D 1,00

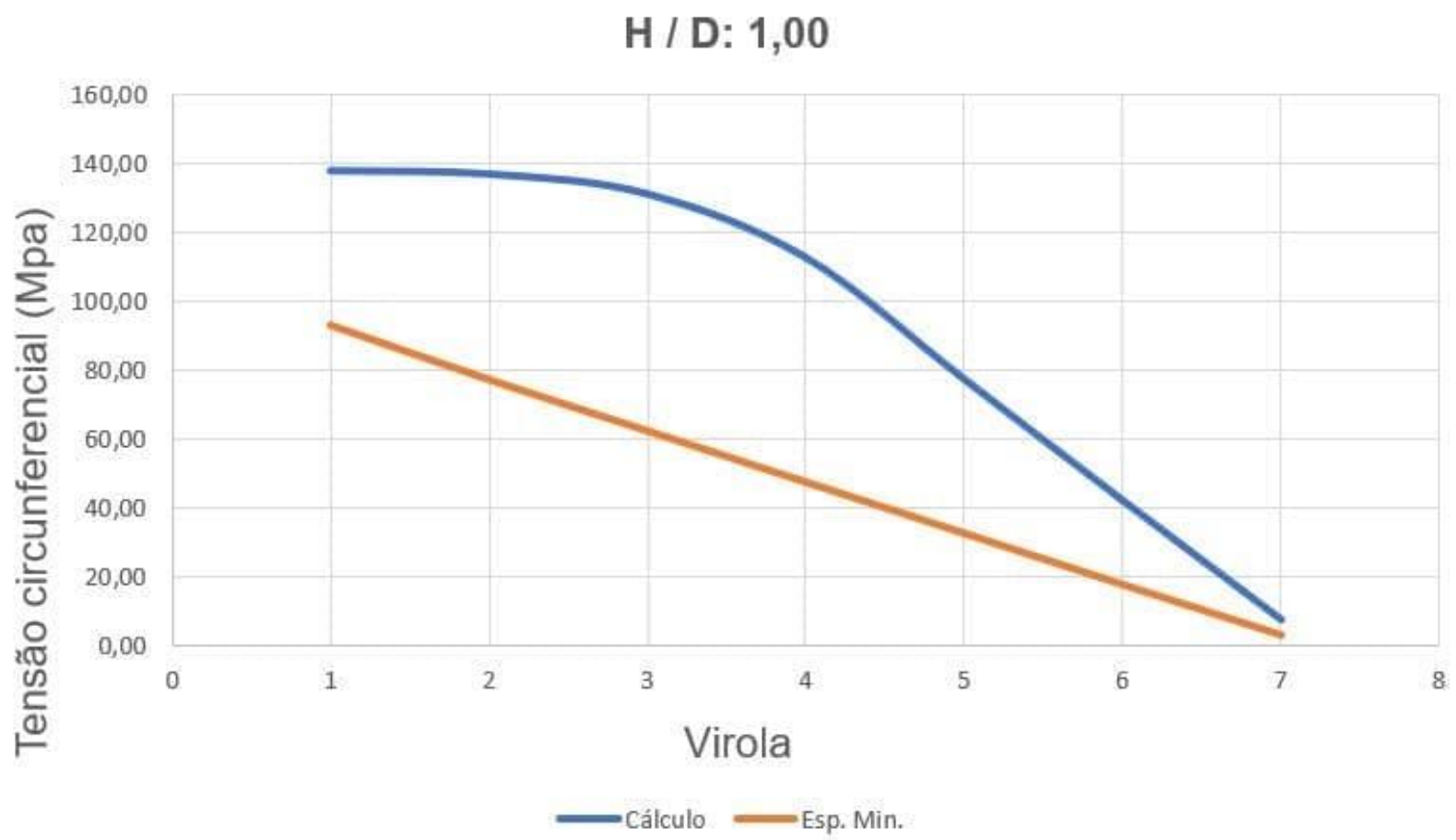

Fonte: O próprio autor

\subsection{TANQUE H/D = 0,50 - DIÂMETRO 7,49 M E ALTURA 14,98 M}

As figuras 25 e 26 apresenta as tensões circunferenciais com as espessuras do tanque calculadas de acordo com a Equação 1 e assumidas como a virola 1 com 4,25 $\mathrm{mm}$, virola 2 com $3,75 \mathrm{~mm}$, virola 3 com $3,35 \mathrm{~mm}$, virola 4 com 3,00, virola 5 com 2,65 $\mathrm{mm}$ e as demais com 2,00 mm. A máxima tensão da virola 1 foi de 146,86 Mpa, menor que a tensão admissível do aço ASTM A36, de 160,00 Mpa, de acordo com a tabela 5-2 da API 650. 
Figura 25 - Tensões circunferenciais H/D 0,50 em 3D - espessuras calculadas

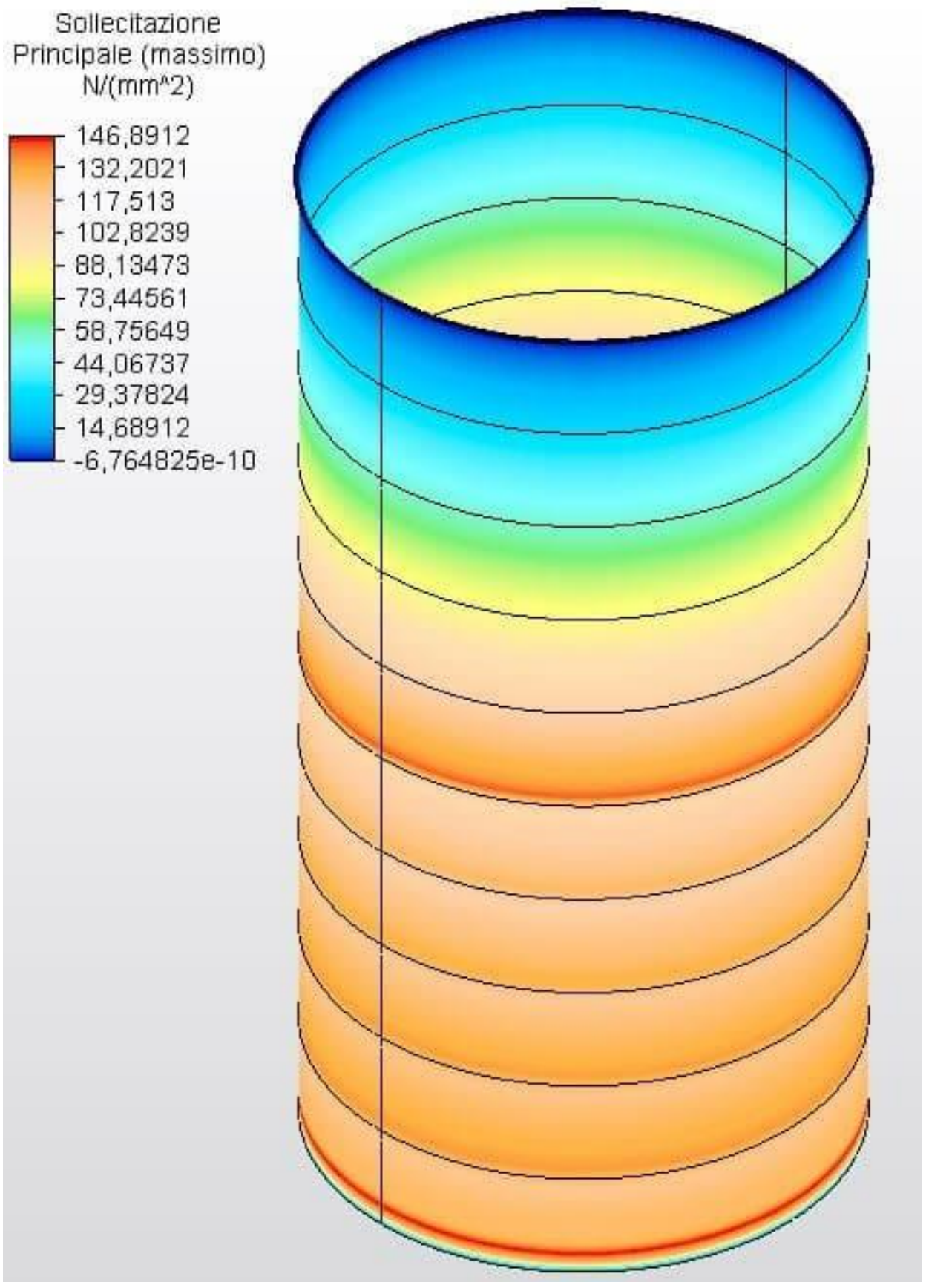

Fonte: O próprio autor 
Figura 26 - Tensões circunferenciais H/D 0,50 em 2D - espessuras calculadas
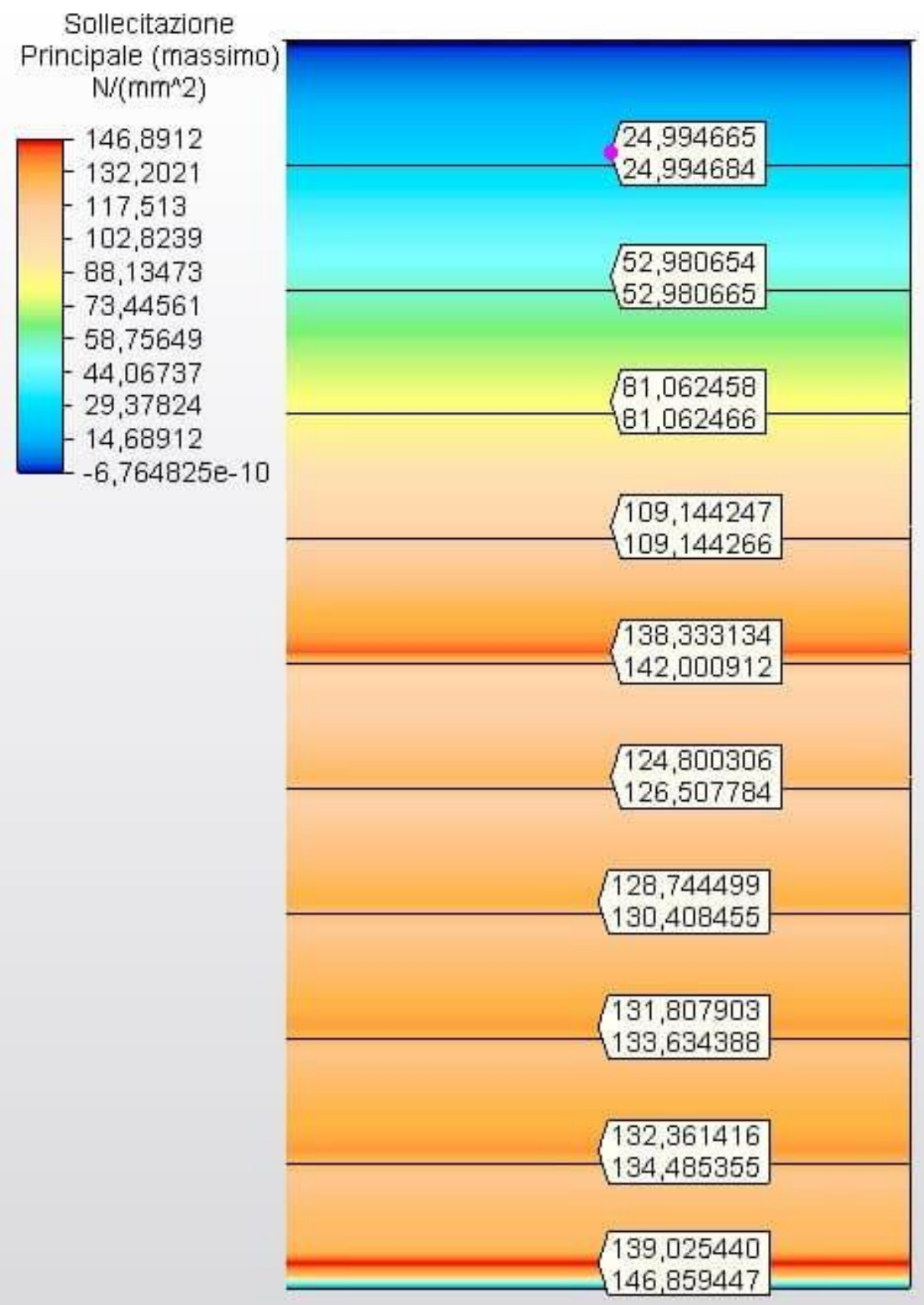

Fonte: O próprio autor

A figura 27 apresenta as tensões circunferenciais com as espessuras do tanque calculadas de acordo com as espessuras mínimas da API 650, no caso 4,75 mm. Tensão máxima foi de 132,09 MPa. 
Figura 27 - Tensões circunferenciais H/D 0,50 em 2D- espessuras minimas

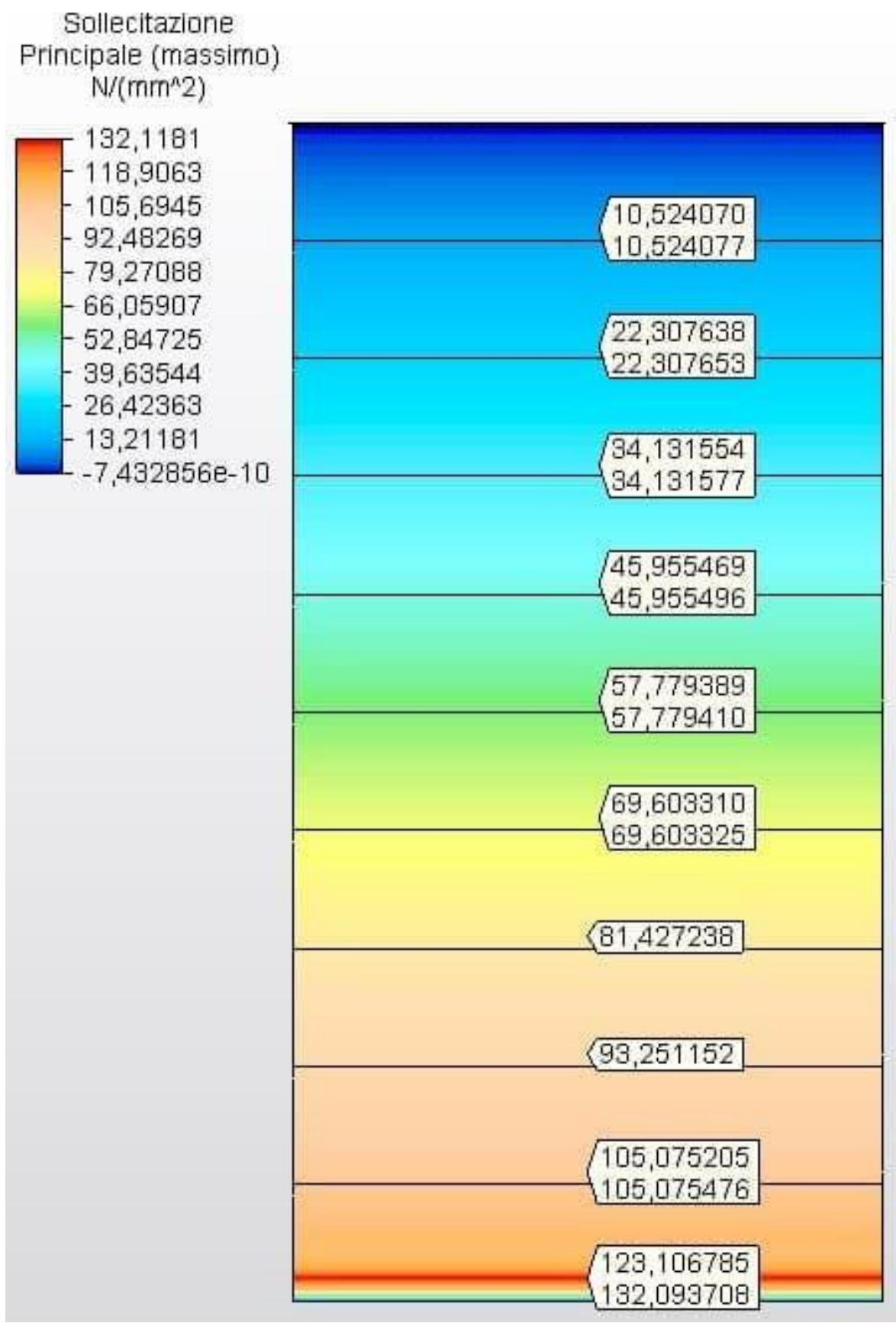

Fonte: O próprio autor

A figura 28 mostra as curvas de tensões circunferenciais, em função das espessuras das virolas e altura de carregamento de água. 
Figura 28 - Curvas das tensões circunferenciais do tanque H/D 0,50

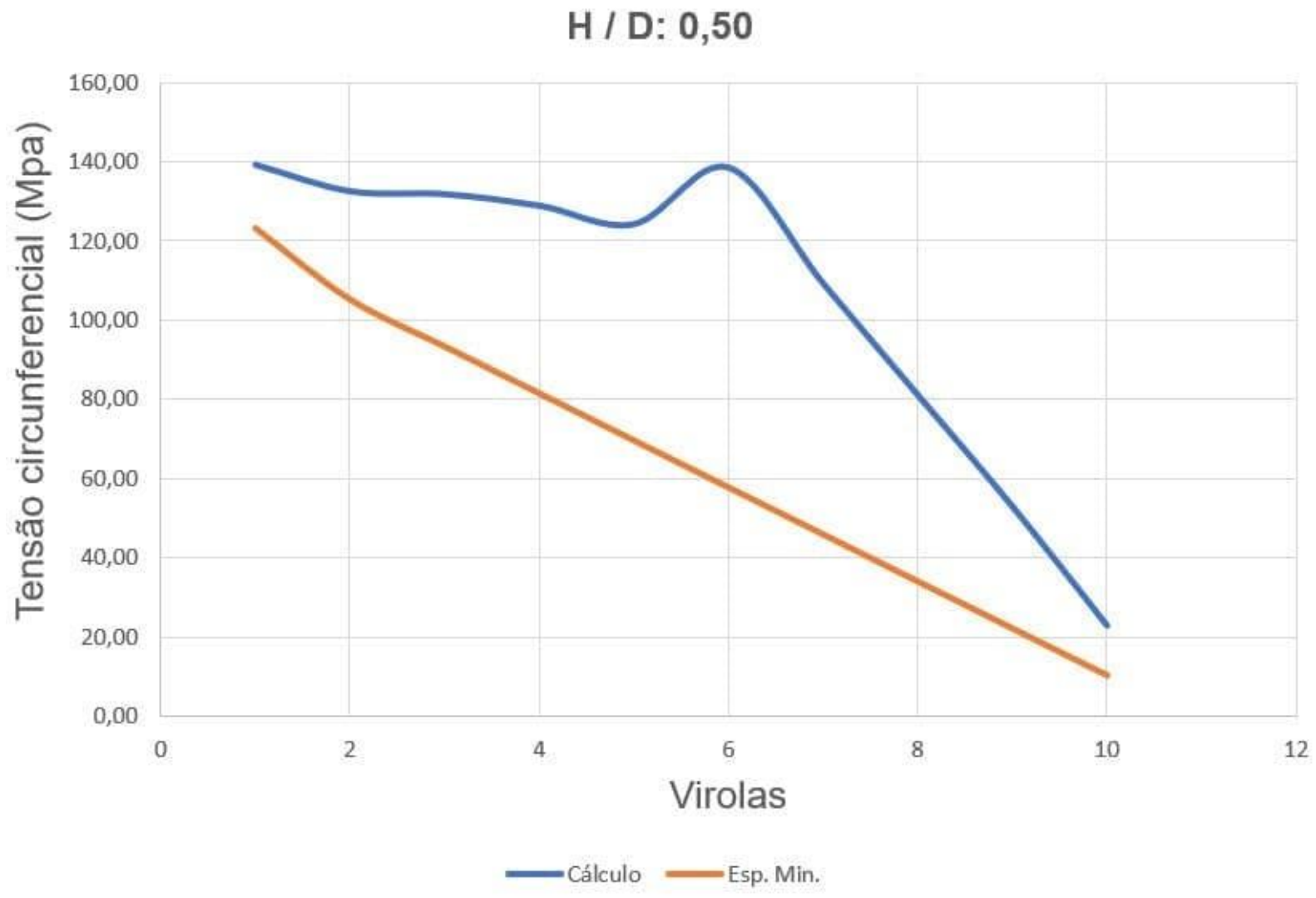

Fonte: O próprio autor

\subsection{TANQUE H/D = 0,25 - DIÂMETRO 5,94 M E ALTURA 23,77 M}

As figuras 29 e 30 apresenta as tensões circunferenciais com as espessuras do tanque calculadas de acordo com a Equação 1 e assumidas como a virola 1 com 6,35 $\mathrm{mm}$, virola 2 com $4,75 \mathrm{~mm}$, virola 3 com $4,25 \mathrm{~mm}$, virola 4 com 4,25, virola 5 com 3,75 $\mathrm{mm}$, virola $6 \mathrm{com} 3,75 \mathrm{~mm}$, virola $7 \mathrm{com} 3,35 \mathrm{~mm}$, virola $8 \mathrm{com} 3,00 \mathrm{~mm}$, virola $9 \mathrm{com}$ 2,65 mm, virola $10 \mathrm{com} \mathrm{2,25} \mathrm{mm} \mathrm{e} \mathrm{as} \mathrm{demais} \mathrm{com} \mathrm{2,00} \mathrm{mm.} \mathrm{A} \mathrm{máxima} \mathrm{tensão} \mathrm{da}$ virola 1 foi de 129,72 Mpa, menor que a tensão admissível do aço ASTM A36, de 160,00 Mpa, de acordo com a tabela 5-2 da API 650. 
Figura 29 - Tensões circunferenciais H/D 0,25 em 3D - espessuras calculadas

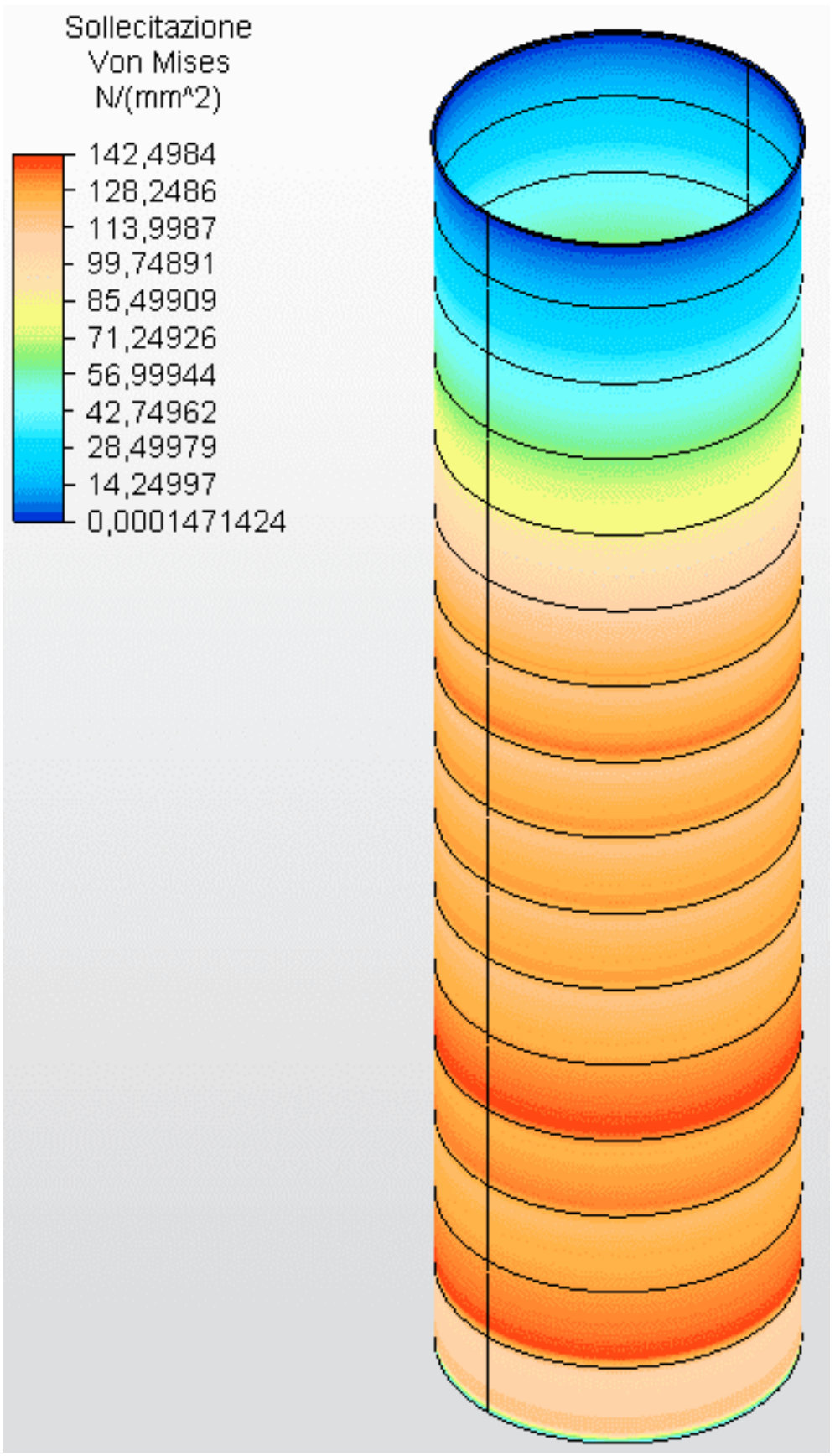

Fonte: O próprio autor 
Figura 30 - Tensões circunferenciais H/D 0,25 em 2D - espessuras calculadas

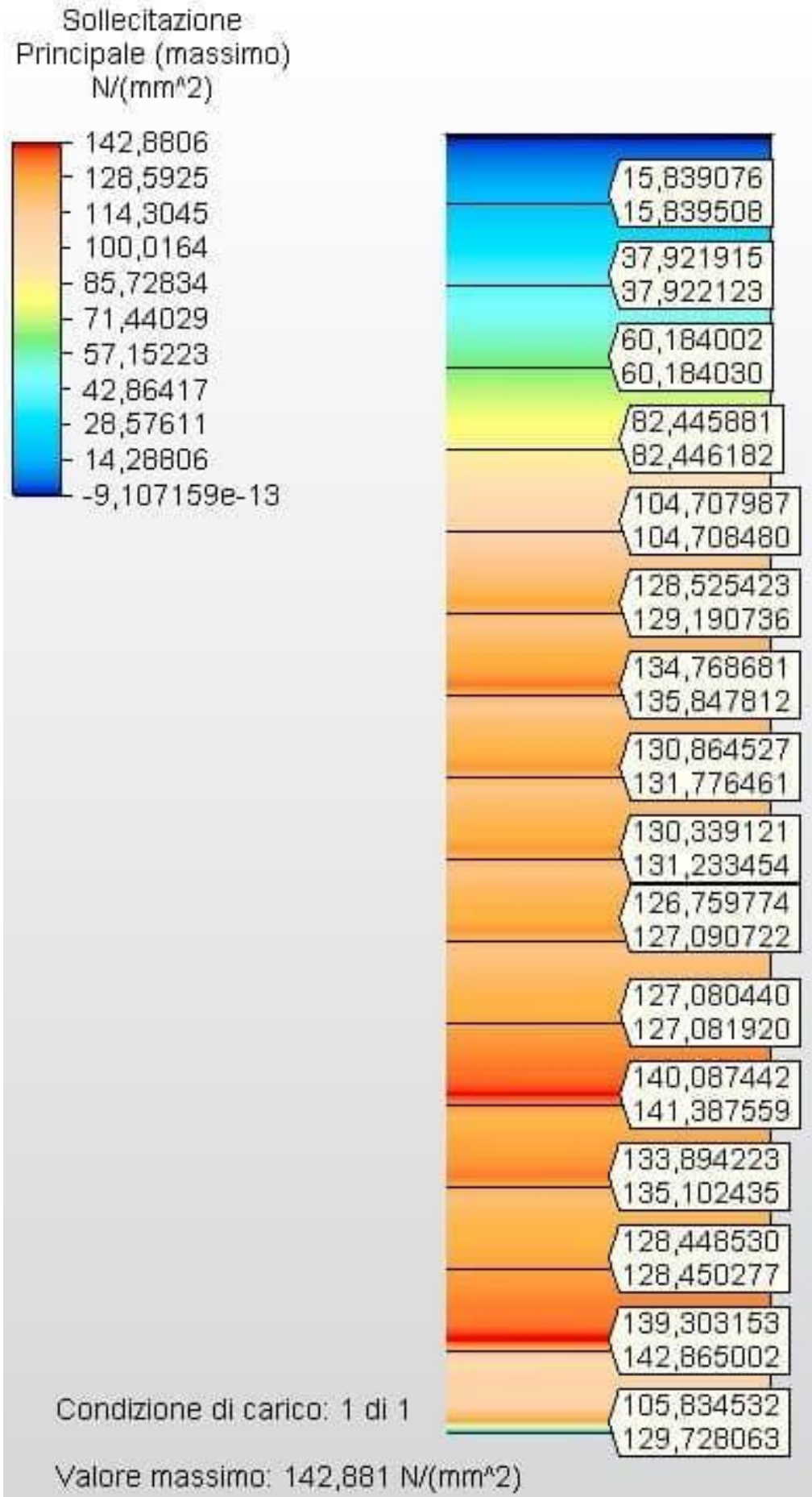

Fonte: O próprio autor 
A figura 31 apresenta as tensões circunferenciais com as espessuras do tanque calculadas de acordo com as espessuras mínimas da API 650, no caso 6,35 mm. Tensão máxima foi de 129,72 MPa.

Figura 31 - Tensões circunferenciais H/D 0,25 em 2D- espessuras minimas

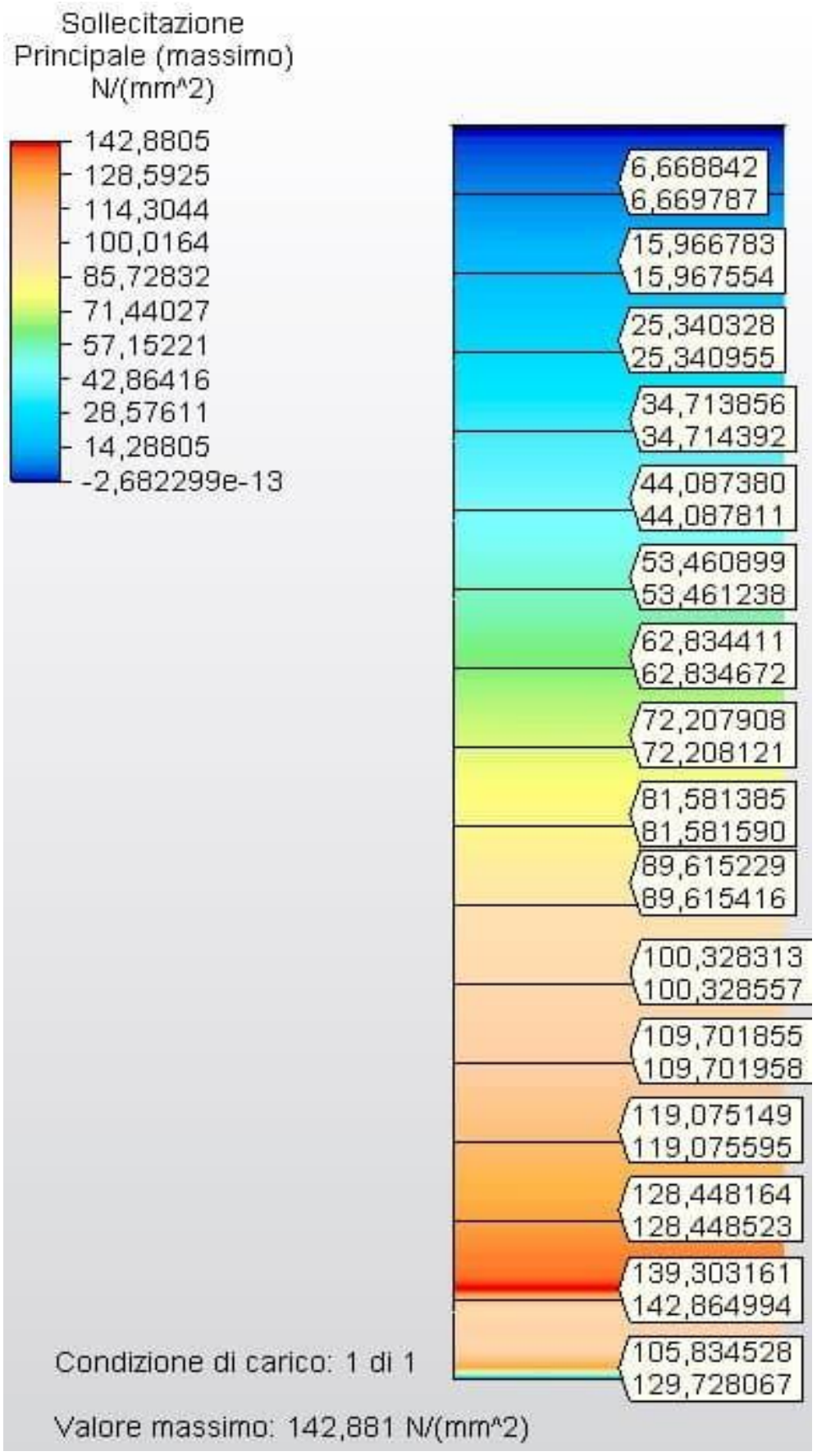

Fonte: O próprio autor 
A figura 32 mostra as curvas de tensões circunferenciais, em função das espessuras das virolas e altura de carregamento de água.

Figura 32 - Curvas das tensões circunferências do tanque H/D 0,25

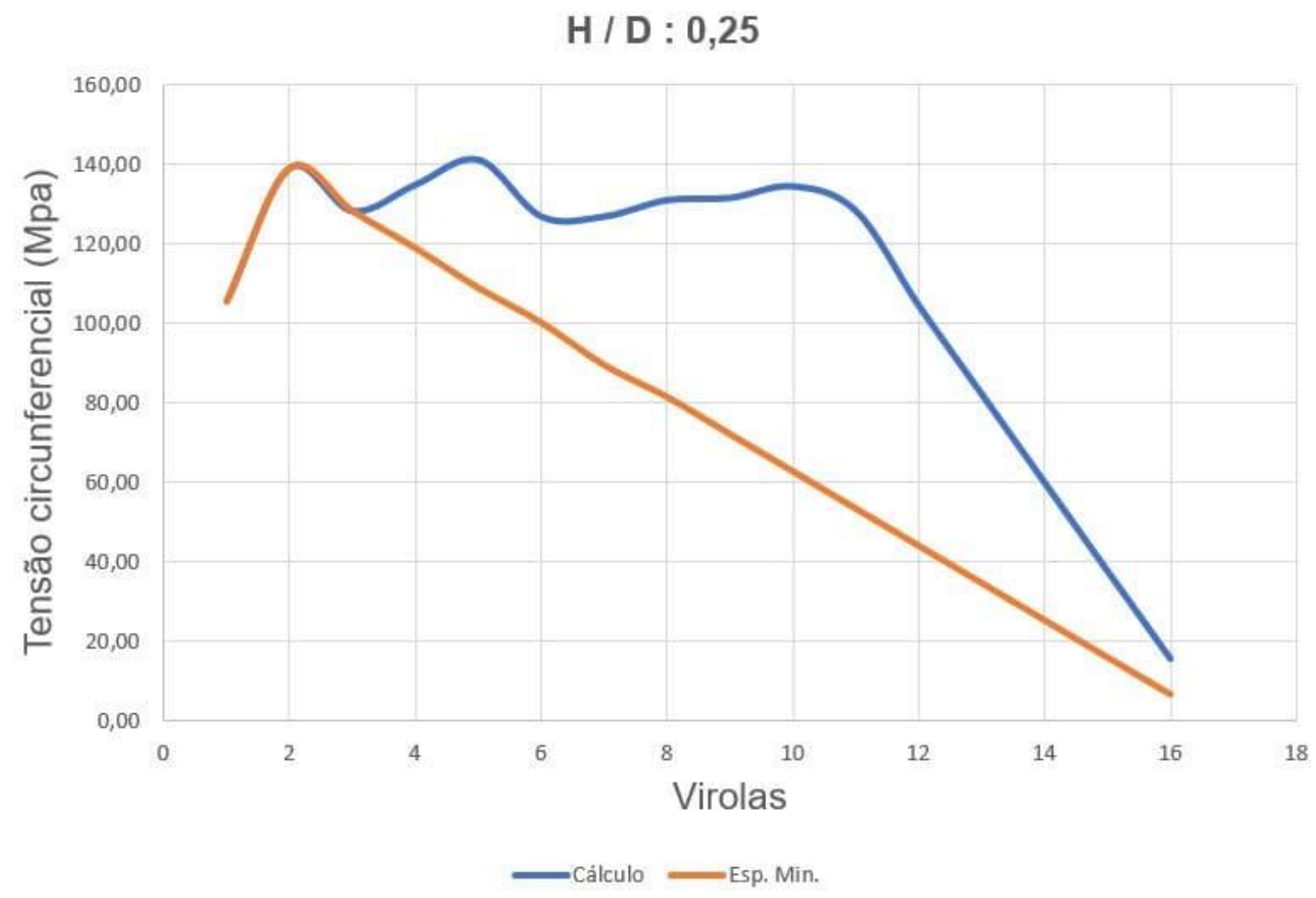

Fonte: O próprio autor

\subsection{CURVA DE FAIXA ÓTIMA DE PESO TOTAL X H/D}

A figura 33 mostra as curvas típicas de peso em função de H/D, para tanques sem teto, de espessuras variáveis, dimensionadas segundo a prescrição da API 650, com aplicação da Equação 1 (curva vermelha) e das espessuras mínimas (curva azul).

A faixa ótima, para os dois critérios de dimensionamento, está entre $H / D=0,75$ a H/D $=2,25$. 
Figura 33 - Curvas típicas de peso de tanques sem teto em função da relação H/D.

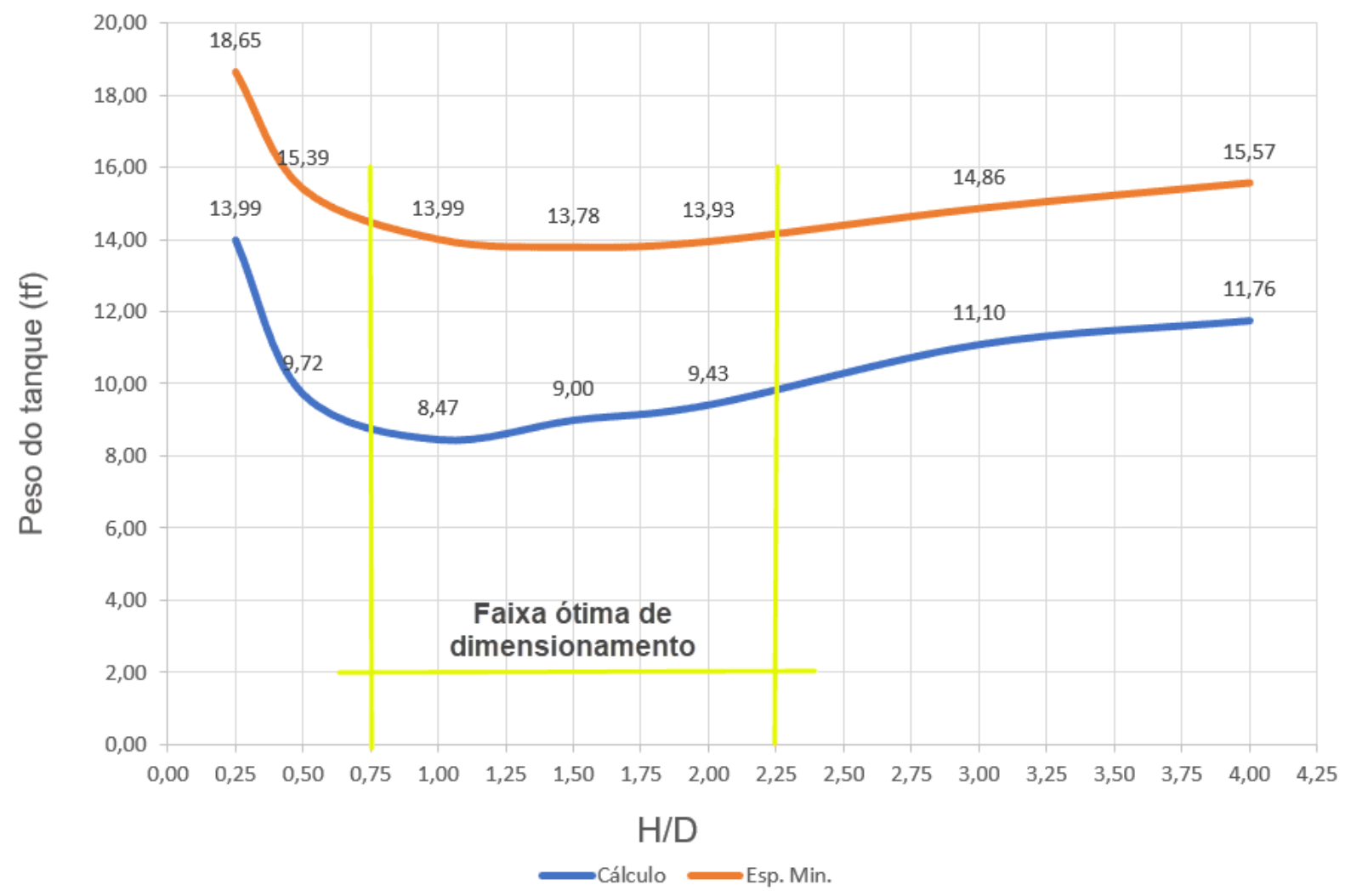

Fonte: O próprio autor

\section{CONCLUSÃO}

Pelos resultados apresentado, conclui-se que é possível, para reservação de agua, estabelecer ótimas relações de H/D que apontam para um peso mínimo do tanque, mesmo considerando os 2 critérios de dimensionamento, ou seja espessuras com apenas a aplicação da Equação 1 e espessuras levando em consideração as espessuras mínimas prescritas pela API 650.

Para dimensionamento de tanques metálicos para reservação de água, onde os critérios de segurança quanto à incêndios e explosões não se aplicam, a utilização do dimensionamento com apenas as espessuras determinadas pela Equação 1 pode ser aceitável, pois as tensões circunferências determinadas pelo MEF foram sempre inferiores à tensão admissível estabelecida na Tabela 5-2 da API 650. 


\section{REFERÊNCIAS}

AMERICAN PETROLEUM INSTITUTE. API Standard 650: Welded steel tanks for oil storage. 12 th ed. Washington DC, 20013.

ASSOCIAÇÃO BRASILEIRA DE NORMAS TÉCNICAS. NBR 7821 - Tanques soldados para armazenamento de petróleo e derivados. Rio de Janeiro. 1983.

AZZUMI, E., GUZEY, S. Comparison of the shell design methods for cylindrical liquid storage tanks. Engineering Structures 101. 2015.

BARROS, S. M. Tanques de armazenamento. Universidade Petrobras. Rio de Janeiro. 2010.

HECKE, M. B. Elementos finitos aplicados à engenharia de estruturas. Reservatórios cilíndricos e silos metálicos. Universidade Federal do Paraná. Curitiba. 2010.

KUAN, S. Y. Design, Construction and Operation of the Floating Roof Tank. University of Soutthern Queensland. Queensland. 2009.

NUNES, C. P. Uma metodologia de projetos de tanques atmosféricos verticais para armazenamento de petróleo e seus derivados. Monografia. Escola de Engenharia da Universidade Federal do Rio Grande do Sul. Porto Alegre. 2013.

RONCETTI, L. Otimização estrutural e econômica de tanques de armazenamento construídos em aço. Anais do 66ํㅡ Congresso Anual da Associação Brasileira de Metalurgia e Materiais - ABM. São Paulo. 2011.

SATO, A. K. Projeto de um tanque de armazenamento atmosférico com teto flutuante para estocagem de gasolina. Trabalho de graduação. Faculdade de Engenharia do Campus de Guaratinguetá, UNESP. Guaratinguetá, 2015.

ZICK L.P., MCGRATH R.V. Design of large diameter cylindrical shells. Proc. Division Refining, AMERICAM PETROLEUM INSTITUTE. New York. 1968. 
Enviado: Abril, 2020.

Aprovado: Maio, 2020. 